\title{
Organ-On-A-Chip in vitro Models of the Brain and the Blood-Brain Barrier and Their Value to Study the Microbiota-Gut-Brain Axis in Neurodegeneration
}

OPEN ACCESS

Edited by:

Maddalena Mastrogiacomo, University of Genoa, Italy

Reviewed by:

Livia Visai,

University of Pavia, Italy Nicole Kerlero De Rosbo,

University of Genoa, Italy

*Correspondence:

Carmen Giordano

carmen.giordano@polimi.it

tThese authors have contributed equally to this work

Specialty section:

This article was submitted to

Tissue Engineering and Regenerative Medicine,

a section of the journal Frontiers in Bioengineering and Biotechnology

Received: 27 June 2019 Accepted: 05 December 2019 Published: 10 January 2020

Citation:

Raimondi I, Izzo L, Tunesi M Comar M, Albani D and Giordano C (2020) Organ-On-A-Chip in vitro

Models of the Brain and the Blood-Brain Barrier and Their Value to Study the Microbiota-Gut-Brain Axis in

Neurodegeneration

Front. Bioeng. Biotechnol. 7:435. doi: 10.3389/fbioe.2019.00435

\author{
Ilaria Raimondi ${ }^{1+}$, Luca Izzo ${ }^{1 \dagger}$, Marta Tunesi ${ }^{1}$, Manola Comar ${ }^{2}$, Diego Albani ${ }^{3}$ and \\ Carmen Giordano ${ }^{1 *}$
}

${ }^{1}$ Department of Chemistry, Materials and Chemical Engineering "Giulio Natta", Politecnico di Milano, Milan, Italy, ${ }^{2}$ SSD of Advanced Translational Microbiology, IRCCS "Burlo Garofolo", Department of Medical Sciences (DMS), University of Trieste, Trieste, Italy, ${ }^{3}$ Department of Neuroscience, Istituto di Ricerche Farmacologiche Mario Negri IRCCS, Milan, Italy

We are accumulating evidence that intestinal microflora, collectively named gut microbiota, can alter brain pathophysiology, but researchers have just begun to discover the mechanisms of this bidirectional connection (often referred to as microbiota-gut-brain axis, MGBA). The most noticeable hypothesis for a pathological action of gut microbiota on the brain is based on microbial release of soluble neurotransmitters, hormones, immune molecules and neuroactive metabolites, but this complex scenario requires reliable and controllable tools for its causal demonstration. Thanks to three-dimensional (3D) cultures and microfluidics, engineered in vitro models could improve the scientific knowledge in this field, also from a therapeutic perspective. This review briefly retraces the main discoveries linking the activity of gut microbiota to prevalent brain neurodegenerative disorders, and then provides a deep insight into the state-of-the-art for in vitro modeling of the brain and the blood-brain barrier (BBB), two key players of the MGBA. Several brain and BBB microfluidic devices have already been developed to implement organ-on-a-chip solutions, but some limitations still exist. Future developments of organ-on-a-chip tools to model the MGBA will require an interdisciplinary approach and the synergy with cutting-edge technologies (for instance, bioprinting) to achieve multi-organ platforms and support basic research, also for the development of new therapies against neurodegenerative diseases.

Keywords: microbiota-gut-brain axis, neurodegenerative diseases, in vitro modeling, microfluidics, brain, bloodbrain barrier

\section{THE MICROBIOTA-GUT-BRAIN AXIS AND ITS INVOLVEMENT IN NEUROLOGICAL DISEASES}

Research on microbiota is rooted in Antonie van Leeuwenhoek's pioneering work (XVII century) (Bardell, 1983), but in recent years it has aroused a growing interest. In particular, the gut microbiota has strongly emerged as a key player both in physiological and pathological conditions (Jia et al., 2008). The gut microbiota is a complex and dynamic population of tens of trillions of microbes residing in the gastrointestinal (GI) tract, with a mutualistic relationship with the host. 
In homeostatic conditions, it interacts with the intestinal mucosa and maintains its integrity (Groschwitz and Hogan, 2009), contributes to the development and maturation of the endocrine system (Farzi et al., 2018), influences the migration, functions and population of the immune system and produces neuroendocrine hormones and neuroactive compounds (Holzer and Farzi, 2014). It also influences microglial activation and development (Erny et al., 2015; Fung et al., 2017), astrocyte functions (Fung et al., 2017), the integrity of the blood-brain barrier (BBB) (Braniste et al., 2014; Michel and Prat, 2016), the production of neurotransmitters (Luczynski et al., 2016), and neuroimmune activation (Sampson et al., 2016; Dinan and Cryan, 2017).

The determination and formation of the gut microbiota involves several factors, like stress, diet, smoking, surgery and environment (Biedermann et al., 2013; Tyakht et al., 2013; Jiang et al., 2015; Rodríguez et al., 2015). Its composition may change during life (Thursby and Juge, 2017) and its maintenance during development and maturation is important to prevent inflammation and disorders. For instance, alterations in resident gut microbiota (dysbiosis) activate the immune system (including T-cells) and increase the levels of inflammatory mediators, the permeability of the gut barrier (Groschwitz and Hogan, 2009; Rea et al., 2016) and mucus production, which in turn promote neuroinflammation, neural injury and neurodegeneration (Kowalski and Mulak, 2019).

Möhle et al. have studied the influence of gut dysbiosis on hippocampal neurogenesis. During behavioral tests, they have observed alterations in germ-free (GF) and specific pathogenfree (SPF) mice treated with antibiotics (Al-Asmakh and Zadjali, 2015; Möhle et al., 2016). GF mice are free of all microorganisms and they represent a powerful tool to investigate how microbes affect the host and the relationship between microbiome and disease (Wos-Oxley et al., 2012). Oppositely, SPF mice are free of a defined list of mouse pathogens, depending on the husbandry methods (Hirayama et al., 1990). With respect to controls with gut microbiota, other groups have found alterations in BBB functions and cortical myelination (Hoban et al., 2013; Braniste et al., 2014), defects in gut motility, progressive deficits in fine and gross motor skills, reduced microglial activation, the presence of $\alpha$-syn inclusions and motor deficits (Sampson et al., 2016).

\footnotetext{
Abbreviations: 2D, two-dimensional; 3D, three-dimensional; 5-HT, 5hydroxytryptamine (serotonin); $\alpha$-syn, $\alpha$-synuclein; $A \beta, \beta$-amyloid; $A D$, Alzheimer's disease; ALS, amyotrophic lateral sclerosis; ANS, autonomic nervous system; ASD, autism spectrum disorders; BBB, blood-brain barrier; BCEC, brain capillary endothelial cells; BMAA, $\beta$-methylamino-L-alanine; CNS, central nervous system; cEND, cerebral capillary endothelial cells; EC, endothelial cells; ECM, extracellular matrix; ENS, enteric nervous system; GABA, $\gamma$-aminobutyric acid; GI, gastrointestinal; GF, germ-free; HD, Huntington's disease; HPA, hypothalamic-pituitary-adrenal axis; hPSC, human pluripotent stem cells; hIPS cells, human-induced pluripotent stem cells; LPS, lipopolysaccharide; MEA, multielectrode array; MGBA, microbiota-gut-brain axis; MOAB, miniaturized optically accessible bioreactor; MS, multiple sclerosis; NPC, neural progenitor cells; NSC, neural stem cells; NVU, neurovascular unit; PD, Parkinson's disease; PDMS, polydimethylsiloxane; $\mathrm{P}_{\mathrm{e}}$, permeability; SCFA, short-chain fatty acids; SPF, specific pathogen-free; TEER, trans-endothelial electrical resistance or trans-epithelial electrical resistance; Thy-1, thymocyte differentiation antigen 1; TJ, tight junctions; ZO-1, zonula occludens-1.
}

There is increasing evidence that dysbiosis is involved in several pathological states, including epilepsy (Iannone et al., 2019), inflammatory bowel disease (Tung et al., 2011; Moser et al., 2018), anxiety and depression (Jia et al., 2008; Wang and Kasper, 2014; Foster et al., 2017), autism spectrum disorders (Mayer et al., 2014; Li and Zhou, 2016; Yarandi et al., 2016), schizophrenia (Nemani et al., 2015), and neurodegenerative disorders (Sarkar and Banerjee, 2019), such as Alzheimer's disease (AD) (Vogt et al., 2017; Van Giau et al., 2018), Parkinson's disease (PD) (Foster and McVey Neufeld, 2013; Nemani et al., 2015; Sampson et al., 2016; Harach et al., 2017) and multiple sclerosis (MS) (Cekanaviciute et al., 2017; Mowry and Glenn, 2018). In fact, the bidirectional microbiota-gut-brain communication (the socalled microbiota-gut-brain axis, MGBA) is not limited to digestive functions and satiety, but the gut microbiota also influences behavior and cognitive abilities (Di Meo et al., 2018; Cryan et al., 2019).

$\mathrm{AD}$ leads to a progressive and irreversible decline in memory and a deterioration of cognitive abilities. It involves the destruction of nerve cells and neural connections in the cerebral cortex, with a significant loss of brain mass. Its hallmarks are intracellular neurofibrillary tangles (Arriagada et al., 1992; Reitz et al., 2011) and extracellular senile plaques mainly composed of $\beta$-amyloid (A $\beta$ ) (Scheuner et al., 1996; Shankar et al., 2008). Kowalski and Mulak reviewed the results in both animal models and clinical trials, supporting the evidence of a correlation between dysbiosis and AD (Kowalski and Mulak, 2019). For instance, APP/PS1 mice are a mouse model of early-onset AD. They are double-transgenic mice expressing the KM670/671NL Swedish mutation of human amyloid precursor protein and the L166P mutation of human presenilin 1 under the control of thymocyte differentiation antigen 1 (Thy-1) promoter and they show an age-dependent accumulation of parenchymal A $\beta$ plaques, with minimal vascular $A \beta$. With respect to age-matched wild-type controls, Firmicutes and Bacteroidetes increased in APP/PS1 mice, while Allobaculum and Akkermansia decreased (Harach et al., 2017).

PD affects the dopaminergic neurons in the substantia nigra and impairs motor control. Its pathological hallmark is the deposition of $\alpha$-synuclein ( $\alpha$-syn) in susceptible neurons in the form of Lewy bodies and Lewy neurites (Dauer and Przedborski, 2003). This accumulation also leads to an increase in intestinal permeability and to the possible translocation of bacterial or microbial inflammatory compounds into the bloodstream (Forsyth et al., 2011; Perez-Pardo et al., 2017). Some studies have hypothesized that $\alpha$-syn is involved in GI dysfunctions and damage to enteric neurons by showing its accumulation in the enteric nervous system (Braak et al., 2006; Forsyth et al., 2011; Gold et al., 2013; Gelpi et al., 2014), whose neurons are specifically associated with the GI tract to control several activities, such as mucosal transport, secretion and modulation of immune and endocrine functions (Gold et al., 2013; SánchezFerro et al., 2015).

MS is an inflammatory, autoimmune disease characterized by damage to the myelin sheaths, axonal degeneration, atrophy of nerve fibers and progressive neuronal loss. Recent studies have highlighted the possibility that some bacterial taxa are 
significantly associated with MS. For instance, Akkermansia muciniphila and Acinetobacter calcoaceticus (known to induce proinflammatory responses in human peripheral blood mononuclear cells and mono-colonized mice) were increased in MS patients, while Parabacteroides distasonis (which stimulates anti-inflammatory interleukins in humans and mouse models) was reduced (Cekanaviciute et al., 2017; Mowry and Glenn, 2018). In addition, they have suggested an effect of probiotics, with an increase of taxa like Lactobacillus, Streptococcus, and Bifidobacterium in both controls and MS patients (Tankou et al., 2018).

The neurodegenerative disorders reported above are just examples of how the microbiota can impact on the brain and its severe and long-lasting diseases and researchers are now beginning to investigate how this may happen in terms of pathophysiological mechanisms in a wide list of brain diseases (De Caro et al., 2019a,b).

\section{COMMUNICATION PATHWAYS IN THE MGBA}

The bidirectional communication among the microbiota, the gut and the brain exploits neural messages from the vagus nerve and spinal afferent neurons, the release of microbial factors, gut hormones and cytokines from the immune system (Holzer and Farzi, 2014; El Aidy et al., 2015; Mayer et al., 2015; Sherwin et al., 2016; Lerner et al., 2017; Farzi et al., 2018). It takes place by distinct pathways involving the autonomic nervous system (ANS), the enteric nervous system (ENS), the hypothalamicpituitary-adrenal axis (HPA), the neuroimmune system and metabolites translocating from the intestinal mucosa into the bloodstream (Grenham et al., 2011; Bhattacharjee and Lukiw, 2013; Borre et al., 2014; Daulatzai, 2014; Stilling et al., 2014).

The ANS is a component of the peripheral nervous system and divides into sympathetic and parasympathetic system. It connects visceral response and central activity and it regulates mucus secretion and motility, gastric secretions, the production of bicarbonate and gut antimicrobial peptides, the absorption and release of fluids by epithelial cells, the permeability of intestinal cells, and mucosal immune response against pathogens (Tougas, 1999; Mayer, 2011; Martin et al., 2018). It transmits efferent signals from the central nervous system (CNS) to the intestinal walls and afferent signals from the intestinal lumen to the CNS through enteric, spinal and vagal pathways (Carabotti et al., 2015). The vagal afferent fibers spread to all the layers of the intestinal wall, but they do not cross the innermost layer (Wang and Powley, 2007). They receive signals from the microbiota only indirectly, by released metabolites or bacterial compounds and the epithelial cells transducing luminal signals (Bonaz et al., 2018). The communication pathway based on the ANS can influence the expression of $\gamma$-aminobutyric acid (GABA) receptors and reduce anxiety and depressive behavior (Bravo et al., 2011). Thanks to the autonomic-related projection of the neurons, stress inhibits the vagus nerve and stimulates the sympathetic system (Taché and Bonaz, 2007; Wood and Woods, 2007). After acute stress, there is an increase in the release of pro-inflammatory cytokines (Marsland et al., 2017), while the afferent fibers of the vagus nerve have anti-inflammatory properties due to the stimulation and involvement of several pathways. The influence of these opposite effects can cause the loss of the protective effect, leading to dysbiosis and disruption of the homeostasis of the epithelial barrier (Bonaz et al., 2013). So far, in vitro models able to reproduce this anatomical pathway are not available, mainly because it is strictly connected with other communication pathways, the connections are complex and it involves the release of different factors from the gut.

The ENS is one of the main divisions of the ANS, but from a functional point of view, it can be regarded as a separate part. It regulates the motor and secretory functions of the GI, and it is involved in the maintenance of the GI homeostasis by allowing the crosstalk among the brain, the gut microbiota, the endocrine and the immune systems. It is the target of bacterial metabolites, so individual microbes and strains could influence its activity and neurochemistry. Ion and fluid secretion from the gut, epithelial barrier and mucus layer protect the ENS from lumen content and separate from the gut microbiota (Saulnier et al., 2013). In GF mice on postnatal day 3, the neurochemical profile and function of the ENS decrease during the development of the enteric neural network compared to SPF mice or dams colonized with microbiota (Collins et al., 2014; Lomasney et al., 2014), suggesting that microbiota influences the development of the ENS (Hyland and Cryan, 2016). The ENS is also referred to as a second brain, because it is involved in the production of neurotransmitters. Enteroendocrine cells of the GI tract produce about $90-95 \%$ of the total body 5-hydroxytryptamine (5-HT, serotonin) (Kim and Camilleri, 2000), that plays an important role in the regulation of GI motility and secretion. Recent studies in GF mice colonized with physiological mouse microbiota have reported that the production of neuronal and mucosal 5-HT and the proliferation of enteric neuronal progenitors correlate to a modification of the neuroanatomy of the ENS and an increase in intestinal trafficking (Grider and Piland, 2007; De Vadder et al., 2018). An in vitro system modeling the ENS is available. It exploits a Transwell ${ }^{\circledR}$-based culture plate and the co-culture of murine small intestinal stem cells, ENS neurons and glia or subepithelial myofibroblasts and it is able to catch the important relationship between enteric population and the functions of the intestinal barrier (Schlieve et al., 2017; Workman et al., 2017; Puzan et al., 2018).

The HPA is the main neuroendocrine system. It regulates different body processes, such as digestion, energy, immune system, and emotions (Sudo, 2012) and it coordinates the adaptive responses to stress by the release of hormones (Tsigos and Chrousos, 2002). During stress, the composition of the gut microbiota changes in response to the release of neuroendocrine hormones (e.g., norepinephrine, dopamine). They increase the growth of Gram-negative bacteria (Lyte et al., 2011), with a consequent increase in the permeability of the intestinal barrier, inducing an inflammatory response and bacterial translocation across the intestinal lumen (De Punder and Pruimboom, 2015). During stress, GF mice release more corticosterone and adrenocorticotrophic hormone than SPF ones, indicating a higher degree of anxiety and stress (Foster and McVey Neufeld, 2013). The gut microbiota also influences the limbic system by producing serotonin and related metabolites (Clarke et al., 2013). 
Several in vitro studies have focused on modeling the HPA and its role. Generally, they are computational (Hosseinichimeh et al., 2015), while experiments have involved treatments with hormones and the evaluation of their effect on cell populations (Al-Asmakh and Zadjali, 2015).

The neuroimmune system regulates the interactions between the nervous and immune systems in both physiological and pathological conditions and it protects the brain against pathogens. The endocrine system permits the passage of information from the nervous system to the immune one, while in the opposite direction the communication exploits inflammatory molecules. The pathway based on the neuroimmune system is important in psychiatry and immunology, as alterations may have pathological consequences and trigger several disorders (Dantzer, 2018). In vivo studies in neurodegeneration models have proved the influence of the gut microbiota on the development and functions of the immune cells of the CNS. For instance, in GF mice, microglia may react sooner to pathogen exposure, but integration with a complex microbial community lowers this reaction to standard levels (Erny et al., 2015). In AD patients, an increase in the brain levels of inflammation-related proteins and alterations of the circulating levels of anti-inflammatory and pro-inflammatory cytokines can directly affect brain functions, mood, and behavior and elicit neuroinflammation (Rothhammer et al., 2018). Furthermore, alterations of the intestinal microbiota can induce inflammation and aggregation of cerebral $\mathrm{A} \beta$ (Pistollato et al., 2016).

The gut microbiota produces different metabolites that translocate, by direct or indirect passage, from the intestinal mucosa to the systemic circulation and may interfere with the $\mathrm{BBB}$ homeostasis and potentially contribute to trigger inflammation and neurodegeneration (Logsdon et al., 2018).
In the case of direct passage, specific immune responses mediated by nerve cells and cellular barriers (e.g., the BBB) protect the brain against microbial invasion. These barriers also allow the delivery of nutrients, the removal of metabolites and the protection of the brain from abrupt changes in blood biochemistry (Dando et al., 2014). Their alteration may modify the CNS homeostasis and change the release and expression of cytokines, chemokines and cell adhesion molecules, or induce cytotoxicity and apoptosis (Kim, 2008). In this case, the pathogenic microorganisms may target different regions, depending on the pathway of invasion, the distribution of cellular receptors and the metabolic environment required for their replication (Kristensson, 2011).

In the case of indirect passage, soluble biochemical factors released by microbes (secretome) can reach the $\mathrm{BBB}$ and then the brain (Matsumoto et al., 2013), showing a neurotoxic effect and altering brain homeostasis (Table 1). Cyanobacteria produce $\beta$-methylamino-L-alanine (BMAA), a non-protein neurotoxic amino acid that can trigger pathological processes (e.g., protein misfolding and aggregation, oxidative stress) frequently observed in neurodegeneration (Brenner, 2013; Karlsson et al., 2014). Lipopolysaccharide (LPS) has also been found in several neurodegenerative conditions. It is a component of the external cell membrane of Gram-negative bacteria. It induces an immune response and increases the permeability of the BBB (Qin et al., 2007; Tufekci et al., 2011; Asti and Gioglio, 2014). Oppositely, short-chain fatty acids (SCFA, especially butyrate, propionate and acetate) derive from the fermentation of dietary fibers and are involved in GI functions, neuroimmune regulation, and host metabolism. For instance, butyrate promotes the absorption of minerals (Rivière et al., 2016), stimulates mucin production (Finnie et al., 1995; Van den Abbeele et al., 2013), induces the expression of antimicrobial peptides (Ochoa-Zarzosa et al.,

TABLE 1 | Bacteria release neuromodulators.

\begin{tabular}{|c|c|c|c|}
\hline Neuro-modulators & Bacterial genera & Brain disease & References \\
\hline $\begin{array}{l}\text { 5-Hydroxytryptamine } \\
(5-\mathrm{TH})\end{array}$ & $\begin{array}{l}\text { Candida, Enterococcus, Escherichia, } \\
\text { Streptococcus }\end{array}$ & anxiety, depression, MS, PD & $\begin{array}{c}\text { Baganz and Blakely, 2013; Mawe and } \\
\text { Hoffman, 2013; O'Mahony et al., 2015; } \\
\text { Yano et al., } 2015\end{array}$ \\
\hline$\beta$-Methylamino- $L$-alanine (BMAA) & Cyanobacteria & $A D, A L S, P D$ & Meneely et al., 2016; Delcourt et al., 2017 \\
\hline$\gamma$-Aminobutyric (GABA) & Bifidobacterium, Lactobacillus & AD, anxiety, depression & $\begin{array}{l}\text { Barrett et al., 2012; Lin, 2013; Hu et al., } \\
\text { 2016 }\end{array}$ \\
\hline Acetylcholine & Lactobacillus & $A D$ & $\begin{array}{l}\text { Wessler and Kirkpatrick, 2008; Wall et al., } \\
2014\end{array}$ \\
\hline $\begin{array}{l}\text { Catecholamine (Adrenaline, } \\
\text { Dopamine, Noradrenaline) }\end{array}$ & Bacillus, Escherichia, Saccharomyces & ASD, depression, PD, schizophrenia & $\begin{array}{c}\text { Mayer and Hsiao, 2017; Mittal et al., 2017; } \\
\text { Sugama et al., } 2017\end{array}$ \\
\hline Histamine & $\begin{array}{l}\text { Lactobacillus, Lactococcus, Pediococcus, } \\
\text { Streptococcus, Enterococcus spp. }\end{array}$ & $\mathrm{AD}, \mathrm{MS}$ & $\begin{array}{l}\text { Landete et al., 2008; Thomas et al., 2012; } \\
\text { Naddafi and Mirshafiey, 2013; Westfall } \\
\text { et al., } 2017\end{array}$ \\
\hline Lipopolysaccharide (LPS) & Gram-negative bacteria & $\begin{array}{l}\text { AD, anxiety, ASD depression, HD, } \\
\text { MS, PD, schizophrenia, etc. }\end{array}$ & Zhao et al., 2017 \\
\hline $\begin{array}{l}\text { Short-chain fatty acids (SCFA, e.g., } \\
\text { acetate, propionate and butyrate) }\end{array}$ & $\begin{array}{l}\text { Bacteroides, Bifidobacterium, } \\
\text { Clostridium, Eubacterium, Lactobacillus, } \\
\text { Propionibacterium, Roseburia Prevotella }\end{array}$ & $A D, A S D, H D, P D$ & $\begin{array}{c}\text { Liu et al., 2015; Verbeke et al., 2015; } \\
\text { Bourassa et al., 2016; Ho et al., 2018; Van } \\
\text { de Wouw et al., } 2018\end{array}$ \\
\hline Gingipains & Porphyromonas gingivalis & $A D, P D$ & Adams et al., 2019; Dominy et al., 2019 \\
\hline
\end{tabular}

Summary of the most important neuropeptides involved in brain disorders such as anxiety, autism, AD, amyotrophic lateral sclerosis, depression, MS, schizophrenia, and PD. 
2009; Guaní-Guerra et al., 2010), contributes to the regulation of intestinal cell growth and differentiation (Barnard and Warwick, 1993; Schröder et al., 1999), regulates the gut immune system (Furusawa et al., 2013) and increases the expression of tight junction (TJ) proteins in the BBB.

Further studies in a gut-unrelated microbiota context have highlighted the relevance of indirect passage for neurodegeneration. For instance, research focused on animal models of periodontitis and brain tissues from $\mathrm{AD}$ patients have indicated that Porphyromonas gingivalis (a Gram-negative periodontal pathogen) and its proteolytic enzymes called gingipains can translocate to the brain (Dominy et al., 2019). Gingipains are cysteine proteases normally mediating the toxicity of $P$. gingivalis for fibroblasts, endothelial (EC) and epithelial cells (Sheets et al., 2005; Stathopoulou et al., 2009; Kinane et al., 2012). However, Adams et al. have reported that they are also present in the blood of $\mathrm{PD}$ patients, suggesting that they can have a role in PD pathology (Adams et al., 2019).

Taking into consideration all the possible communication pathways between the microbiota and the brain that we have described so far, it is quite apparent that the route based on the passage of soluble microbial secretome from the microbiota to brain cells is actually the most reproducible pathway to model the MGBA in vitro. Nowadays, organ-ona-chip technology represents a promising strategy to model this multi-organ communication and researchers have mainly focused on mimicking the MGBA by exploiting several in vitro models connected to each other to allow the diffusion of soluble factors and/or metabolites. Because of their complex structure and functional mechanisms, the $\mathrm{BBB}$ and the brain are very challenging to model for today's technological tools. For instance, the need for three-dimensional (3D) perfused cell cultures and the difficulties of managing co-cultures of different cell populations are just examples of this complexity when modeling these two human compartments. Thus, if the main purpose is to study the effects of the secretome produced by the gut microbiota on the $\mathrm{BBB}$ and the brain, we have to develop more advanced and reliable systems to overcome the technical weaknesses that hinder the modeling of multi-organ communication.

Organs-on-a-chip offer several advantages (Bhatia and Ingber, 2014; Ingber, 2016). They provide spatially-oriented cell-cell interactions and exposure to physical factors, such as fluid flow, shear stress and strain. By perfusing the medium inside the culture chambers, they guarantee a physiological exchange of nutrients and metabolites and shear stress values suitable to stimulate cell growth, proliferation, and differentiation. Furthermore, the miniaturization reduces the amount of reagents needed, and the possibility of integration with electronic devices (e.g., electrodes, sensors) allows to measure biological and physical parameters (e.g., cell viability, trans-epithelial electrical resistance, oxygen pressure, and $\mathrm{pH}$ ) while in culture.

The literature describes several organs-on-a-chip modeling the human brain and the BBB. In the following paragraphs, we will present the forefront devices and their peculiar features, highlighting their great potential, but also their current limitations.

\section{MODELING THE BRAIN: FOCUS ON ORGAN-ON-A-CHIP-BASED IN VITRO MODELS}

The brain is the central organ of the nervous system. It is protected by the skull and other anatomical structures, such as the $\mathrm{BBB}$ and the meninges, a layer of membranes covering the CNS. However, pathogens can reach the brain when inflammation alters these protective barriers.

The brain controls all body functions and integrates information from the environment. It comprises several structures mainly made up of two cell populations: nerve cells (neurons) and glial cells.

Neurons are composed of a cell body, dendrites (picking up the messages from other nerves), and an axon (transmitting impulses from the cell body to the periphery). They communicate by several connections (synapses) that allow the passage of nerve impulses. The neuronal circuitry is composed of afferent and efferent pathways that send information by chemical or electrical signals. In chemical synapses, the signals propagate by the release of neurotransmitters, while electrical signals are due to action potentials caused by different ions crossing the neuronal membrane. They are important for the transmission of information that exploits currents flowing along the membrane of the axon to the synapses (Kandel et al., 2012).

Glial cells provide protection, nourishment and structural support to neurons. They comprise astrocytes, microglia, oligodendrocytes, and ependymal cells. For instance, astrocytes play a key role in promoting neuronal survival and maintaining brain homeostasis and the structure of the BBB. Microglia have immune system-like activity. They protect the brain from infections and clean up cell residues (e.g., debris). Oligodendrocytes are essential for neuronal myelination and they contribute to the regulation of the concentration of extracellular ions. However, they are rarely included in in vitro models (Jäckel et al., 2017). Ependymal cells are important for the production of cerebrospinal fluid and other substances, but they are included in in vitro models only when they are the focus of the model itself (Jäckel et al., 2017). For instance, frequently models focusing on the neurovascular unit (NVU) include ependymal cells.

Researchers have studied brain structure and functions extensively, but including the different cell populations and considering its surface dimensions when modeling the entire brain is an enormous challenge. They have started with single cell cultures, neglecting the possible interactions between neurons and glial cells. More recently, they have moved to the study of cell-cell interactions and improved the mimicking of natural tissue in both physiological and pathological conditions. For instance, co-cultures have supported the study of physical communication between cells (Skaper and Facci, 2012, 2018), Transwell ${ }^{\circledR}$ permeable supports have been used to investigate direct cellular communication in the absence of physical contact and conditioned medium has allowed to assess cell interactions in the absence of physical contact by examining the biochemical factors released (Yoshida et al., 1995; Lin et al., 2016). 
3D cultures have contributed to address innovative treatments and enhance clinical translation (Shamir and Ewald, 2014; Hopkins et al., 2015; Hasan and Berdichevsky, 2016). For instance, Tang-Schomer et al. (2014) have modeled brain cortical architecture and reproduced the compartmentalization of gray and white matter by coupling adhesive-free, concentric silk protein-based porous layers and a collagen gel to support 3D axon connections. Lozano et al. (2015) have also proposed a layer-based approach to fabricate $3 \mathrm{D}$ brain-like structures by bioprinting gellan gum (conjugated to RGD peptide) with primary cortical neurons. In the context of $3 \mathrm{D}$ neural tissue models (Zhuang et al., 2018), bioprinting has demonstrated its potential for the fabrication of constructs embedding glial cells, neurons and stem cells (e.g., Lee et al., 2009; Hsieh et al., 2015; Lozano et al., 2015; Dai et al., 2016; Gu et al., 2016), although the selection of printable materials, cytocompatible with neural cells and able to mimic the mechanical properties of neural tissue while avoiding structural collapse is often difficult.

Thanks to their communicating chambers and dynamic perfusion, organs-on-a-chip are essential tools to support the survival and development of brain tissue, assess cell migration, the direction of axonal extension, transport, and signal transmission.

For instance, Park et al. have proposed a microfluidic chip for the interstitial perfusion of neurospheroids with flow conditions comparable to those in the brain (about $0.1-0.3 \mu \mathrm{L} / \mathrm{min}$ ) and applied as an in vitro model of $\mathrm{AD}$ by testing the toxicity of $A \beta$. Spheroids (but also organoids grown from stem cells) are powerful $3 \mathrm{D}$ biological platforms to investigate neuronal development, drug transport, and the pathogenesis of neuronal diseases. They rely on the capability of small cell aggregates to create in vitro, without any existing pattern or foreign material, polarized floating structures similar to in vivo tissues. They recapitulate more complex cell-cell interactions and have a higher level of functionality (Fennema et al., 2013; Lancaster et al., 2013; McCracken et al., 2014; Dingle et al., 2015; Paşca et al., 2015), but they lack vascularization and cells hardly reach maturation in culture. Park et al. have fabricated their device by bonding cubic poly(dimethylsiloxane) (PDMS) chambers $(1 \times 1 \times 1 \mathrm{~cm})$ by soft lithography. The top part was dedicated to the flow of culture medium, while the bottom one contained an array structure of fifty cylindrical wells (diameter: $600 \mu \mathrm{m}$; height: $400 \mu \mathrm{m}$ ) hosting the neurospheroids. An osmotic micro-pumping system exposed the neurospheroids to a constant flow (about 0.15 $\mu \mathrm{L} / \mathrm{min}$ ). Their results have indicated that the interstitial flow influences the size distribution of neurospheroids, accelerates the differentiation of neural progenitor cells into neurons, and enhances the proliferation of neural progenitor cells and the toxicity of $A \beta$ with respect to static conditions (Park et al., 2015).

Similarly, Wang et al. have developed a microfluidic chip to obtain human-induced pluripotent stem cell (hiPS)-derived brain organoids to study neurodevelopmental disorders at early stages of gestation. They have used conventional soft lithography to fabricate a PDMS-based device with five independent channels. A central perfusion channel ( $1 \mathrm{~mm}$ wide, $20 \mathrm{~mm}$ long) separated two culture channels for the formation and culture of brain organoids ( $2.5 \mathrm{~mm}$ wide, $14 \mathrm{~mm}$ long). Embryonic bodies were immobilized in Matrigel and infused into the culture chambers, while medium in static conditions filled the two remaining external channels. Their results have confirmed that organs-on-a-chip provide a controllable microenvironment for an efficient development, maturation, and extended growth of brain organoids (Wang et al., 2018).

Kilic et al. have used organs-on-a-chip to extend culture time, provide a controllable and reliable microenvironment for the differentiation of human pluripotent cells (hPSC) into neuronal and astroglial cells, and study cell migration in response to gradients of chemotactic cues. Their device showed three PDMS layers attached to a glass substrate for mechanical support and high-resolution imaging. The first PDMS sheet modeled the lumens of blood vessels (vascular compartment) and exhibited support pillars to avoid membrane collapse, the second substrate had a porous PDMS membrane (pore size: $5 \mu \mathrm{m}$ ) as a scaffold for the $\mathrm{BBB}$ and the remaining PDMS substrate modeled the neural tissue (neuronal compartment). The top and bottom compartments had four perfusion channels (two inlets and two outlets for both chambers; $5 \mathrm{~mm}$ wide, $20 \mathrm{~mm}$ long, and $300 \mu \mathrm{m}$ high) (Kilic et al., 2016).

Coupling the BBB to the brain in a single organ-on-achip represents a further improvement toward the development of a complete miniaturized model for drug screening and toxicity. For instance, Koo et al. have exploited a device named OrganoPlate $^{\circledR}$ (MIMETAS, The Netherlands). They have filled the brain chamber with a collagen hydrogel embedding N2a neuroblastoma cells, C8D1A immortalized astrocytes and BV2 immortalized microglia. After gelation, they have defined the $\mathrm{BBB}$ compartment by plating bEnd.3 EC facing the hydrogel. However, in this model a rocker shaker (instead of a micropumping system) ensured fluid flow and shear stresses and fluid flow, and the Authors had to refresh the medium every 2 days (Koo et al., 2018).

Excitability is a key feature of brain cells, therefore the integration of organ-on-a-chip technology with electrodes is fundamental to both stimulate and read-out the burst-firing power and its frequency rate within the constructs. For instance, Soscia et al. have described removable inserts to deposit neurons from different brain areas (e.g., primary rodent hippocampal and cortical neurons) onto defined regions of a commercial microelectrode array (MEA), without the need of physical or chemical barriers. Their system is a miniaturized device lacking perfusion, but the Authors have proposed an effective method to separate distinct neuronal populations on microfabricated devices, and it offers a unique approach to develop a complex cell environment for anatomically-relevant brain-on-a-chip devices (Soscia et al., 2017).

\section{MODELING THE BLOOD-BRAIN BARRIER: FOCUS ON ORGAN-ON-A-CHIP-BASED IN VITRO MODELS}

The properties of the BBB are mainly due to the presence of EC and their interactions with mural, immune, glial and neural cells that in turn interact with the NVU (Abbott et al., 2012; 
Muoio et al., 2014; McConnell et al., 2017). It is made up of neurons, astrocytes, oligodendrocytes, microglia, smooth muscle cells, brain EC and pericytes embedded in the brain extracellular matrix (ECM) and it supports the neuronal circuitry by controlling the permeability of the $\mathrm{BBB}$, the cerebral blood flow and maintaining the chemical composition of the brain interstitial fluid (Zlokovic, 2011).

Transport across the $\mathrm{BBB}$ is crucial to maintain brain homeostasis and occurs by specific and selective mechanisms. The phospholipid bilayer of the plasma membrane permits the passage of small gaseous molecules, lipophilic agents and small polar but uncharged molecules (such as ethanol and $\mathrm{H}_{2} \mathrm{O}$ ), while specific transporters (e.g., solute carriers and $\mathrm{ABC}$ transporters like P-glycoprotein) allow the transfer of hydrophilic molecules (such as glucose). Larger hydrophilic molecules translocate by endocytosis, while the TJ between the EC lining the microvessels of the CNS regulate the paracellular pathway for the movement of ions and molecules in-between cells. In particular, the transmembrane proteins of TJ (e.g., occludins, claudins, and junctional adhesion molecules) are anchored inside the EC by another protein complex, including zonula occludens-1 (ZO-1, also known as tight junction protein-1) and associated proteins (Stamatovic et al., 2008).

In the field of toxicology and drug development against neurological disorders, a number of complex models have been proposed to recapitulate the basic features of the BBB in vitro. They have provided insights into the passage of molecules across the $\mathrm{BBB}$ and its alterations during disease, cell-cell interactions, and the mechanisms leading to neurodegeneration. Key steps in their validation are transport studies with model molecules and the assessment of the integrity of the barrier by TJ immunostaining and the measurement of the TEER. For mammalian BBBs, the physiological values for the TEER ranges from 1,500 to $2,000 \Omega \cdot \mathrm{cm}^{2}$ (Crone and Olesen, 1982; Butt et al., 1990).

Because of its implications in the development of drugs for CNS applications, another fundamental property of the BBB is its permeability. It can be predicted with several computational tools, and measured with different experimental methods. For instance, it is measured with hydrophilic tracers such as sodium fluorescein (376 Da), Lucifer yellow (444 Da), FITC-labeled sucrose, mannitol or dextrans, inulin and bovine serum albumin (Banerjee et al., 2016). In rat models, the permeability of the BBB to sucrose can be as low as $0.03 \cdot 10^{-6} \mathrm{~cm} \cdot \mathrm{s}^{-1}$ (Bickel, 2005). For a given small hydrophilic molecule, a correlation exists between the TEER and permeability, but it depends on the size of the molecule and on experimental factors (e.g., shaking, single point estimation vs. steady-state calculations) (Helms et al., 2016).

In vitro models of the $\mathrm{BBB}$ exploit immortalized or primary brain EC from different animal species, but currently none exhibits a TEER in the physiological range. Primary cultures of human brain EC would be the ideal choice for drug development and preclinical studies, but their limited availability strongly hinders their application. Models based on primary bovine or porcine EC are used to study the transport of small molecules, but the TEER is lower than the physiological ones (Jiang et al., 2019). They can be used for screening studies because their animal sources allow the harvesting of a great number of cells, but the pattern of protein expression differs from that of the corresponding human proteins and in some cases, the experimental barrier shows different affinity and transport rates with respect to the human $\mathrm{BBB}$. Mouse or rat brain $\mathrm{EC}$ are easier to obtain, but the low yield makes their routinely use impractical. For these reasons, the great majority of models is based on mouse EC lines (e.g., bEnd.3, bEnd.5, immortalized mouse cerebral capillary EC, cEND). Human immortalized EC (e.g., CMEC/D3 cells) are also commercially available and they are suitable to study transporters, receptors, signaling pathways and metabolism (Helms et al., 2016). As an alternative, other models exploit self-renewable cells (such as hPSC) that can differentiate into mature somatic cells. Some of these models has provided a good approximation of the physiological BBB, but actually, they are still far to mimic the changes in permeability and drug permeation found in several pathological conditions. Table 2 lists recent two-dimensional (2D) co-cultures based on immortalized or primary cells and it reports their distinctive hallmarks (junction proteins, TEER, permeability). Similarly, Table 3 shows examples of models based on self-renewable cells.

Both tables refer to static conditions based on the Transwell ${ }^{\circledR}$ system, where a microporous semipermeable membrane is suspended in the culture wells. It allows the diffusion of molecules from one side to another and it separates the vascular compartment (EC) from the parenchymal one (e.g., astrocytes). According to the complexity of the model, the cell populations are plated on the plastic well and on the top side of the membrane, on the plastic well and on both sides of the membrane or only on both sides of the membrane (Bors and Erdö, 2019).

Dynamic in vitro models of the BBB offer several advantages over conventional 2D systems, but they require a higher flow rate than in physiological conditions because of the larger volume of the microtubes with respect to brain capillaries. As for the static models, they comprise two chambers (mimicking the vascular and parenchymal compartments) separated by a microporous semipermeable membrane, acting as a physical barrier.

Griep et al. have modeled the BBB to study barrier dysfunctions in neurodegenerative conditions. Their chip was made up of two PDMS layers divided by a Transwell ${ }^{\circledR}$-like polycarbonate membrane (pore size: $0.4 \mu \mathrm{m}$, thickness: $10 \mu \mathrm{m}$ ) to culture CMEC/D3 EC. To measure the TEER, the Author haves included $\mathrm{Pt}$ electrodes inside furrows in the PDMS sheets after assembling the top and bottom parts of the chip (Griep et al., 2013).

Booth and Kim have proposed a more complex microfluidic model of the BBB to study its function and drug delivery. They have developed a multi-layered and fully integrated device, made up of (from top to bottom) a PDMS sheet, a glass electrode layer, a PDMS substrate, a porous polycarbonate membrane for cell culture, another PDMS layer, a glass electrode substrate and finally a last PDMS sheet. The two central PDMS layers hosted the perfusion channels (named as abluminal, the inferior one; and luminal, the superior one). They were perpendicular and their aspect ratios were designed to induce a uniform shear stress distribution on bEnd.3 EC (for the abluminal channel) and minimize the shear stresses on C8D1A astrocytes (for 
TABLE 2 | In vitro models of the BBB, 2D condition.

\begin{tabular}{|c|c|c|c|c|c|}
\hline Cell populations & 2D models & Disease & $\begin{array}{l}\text { Junction } \\
\text { proteins }\end{array}$ & $\begin{array}{l}\sim \operatorname{TEER}\left(\Omega \cdot \mathrm{cm}^{2}\right) \\
\mathrm{P}_{\mathrm{e}} 10^{-6}\left(\mathrm{~cm} \cdot \mathrm{s}^{-1}\right)\end{array}$ & References \\
\hline Primary mouse BCEC + astrocytes & co-culture & - & $\begin{array}{l}\text { occludins, } \\
\text { claudins } 3 \text { and } 5\end{array}$ & $\begin{array}{l}\text { TEER } 800 \\
P_{e} 4.5 \text { (with sucrose) }\end{array}$ & Coisne et al., 2005 \\
\hline Primary rat BCEC + astrocytes & co-culture & $\begin{array}{l}\text { AD, encephalitis, } \\
\text { MS }\end{array}$ & $\begin{array}{l}\text { occludins, } \\
\text { claudins 5, } \\
\text { ZO-I }\end{array}$ & $\begin{array}{l}\text { TEER 300-600 } \\
P_{e} 1.4 \text { (with sucrose) } \\
P_{e} 4.3 \text { (with Lucifer yellow) }\end{array}$ & $\begin{array}{c}\text { Nakagawa et al., 2007, 2009; Perrière } \\
\text { et al., 2007; Abbott et al., } 2012\end{array}$ \\
\hline $\begin{array}{l}\text { Primary rat BCEC + astrocytes + } \\
\text { neurons }\end{array}$ & co-culture & AD, epilepsy & $\begin{array}{l}\text { occludins, } \\
\text { ZO-I }\end{array}$ & TEER 268 & Xue et al., 2013 \\
\hline $\begin{array}{l}\text { Primary bovine BCEC + rat } \\
\text { astrocytes }\end{array}$ & co-culture & - & $\begin{array}{l}\text { Occludins } \\
\text { claudins } 1 \text { and } 5\end{array}$ & $\begin{array}{l}\text { TEER 600-800 } \\
\mathrm{Pe}_{\mathrm{e}} 0.5 \text { (with mannitol) }\end{array}$ & $\begin{array}{l}\text { Gaillard et al., 2000, 2001; Helms } \\
\text { et al., 2010; Helms and Brodin, } 2014\end{array}$ \\
\hline
\end{tabular}

They are based on primary or immortalized cells.

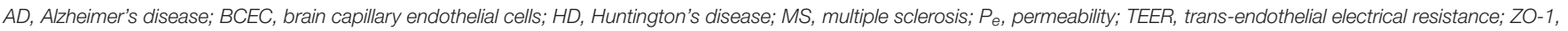
zonula occludens-1.

TABLE 3 | In vitro models of the BBB, 2D condition.

\begin{tabular}{|c|c|c|c|c|c|}
\hline Cell populations & 2D models & Disease & Junction proteins & $\begin{array}{l}\sim \operatorname{TEER}\left(\Omega \cdot \mathrm{cm}^{2}\right) \\
\mathrm{P}_{\mathrm{e}} 10^{-6}\left(\mathrm{~cm} \cdot \mathrm{s}^{-1}\right)\end{array}$ & References \\
\hline hPSC + rat astrocytes & co-culture & $\begin{array}{l}\mathrm{AD}, \mathrm{MS} \text { and brain } \\
\text { tumors }\end{array}$ & $\begin{array}{l}\text { occludins, } \\
\text { claudins 5, } \\
\text { ZO-I }\end{array}$ & $\begin{array}{l}\text { TEER } 700 \\
P_{e} 0.6 \text { (with sucrose) }\end{array}$ & Lippmann et al., 2012 \\
\hline hPSC + pericyte-primed human NPC & co-culture & & $\begin{array}{l}\text { occludins, } \\
\text { claudins 5, } \\
\text { ZO-I }\end{array}$ & $\begin{array}{l}\text { TEER } 5350 \\
P_{e} 0.6 \text { (with sucrose) }\end{array}$ & Lippmann et al., 2014 \\
\hline $\begin{array}{l}\text { hIPS-EC + hIPS-NSC + astrocytes + } \\
\text { pericytes }\end{array}$ & co-culture & $A D, P D$ & $\begin{array}{l}\text { occludins, } \\
\text { claudins } 3,4 \text { and } 5 \text { ZO-I }\end{array}$ & $\begin{array}{l}\text { TEER 433-2,489 } \\
P_{e} 1.58 \text { (with Lucifer yellow) } \\
P_{e} 1.33 \text { (with } \\
\text { sodium fluorescein) }\end{array}$ & Appelt-Menzel et al., 2017 \\
\hline
\end{tabular}

They are based on human-induced pluripotent stem (hIPS) cells or progenitor cells.

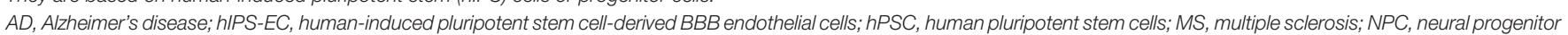
cells; NSC, neural stem cells; PD, Parkinson's disease; $P_{e}$, permeability; TEER, trans-endothelial resistance; ZO-1, zonula occludens-1.

the luminal channel). The electrodes in the glass substrates opposite to the membrane allowed to monitor the TEER. To reduce the noise due to the wiring resistance, the Authors have used two sets of two thin-film $\mathrm{AgCl}$ electrodes forming a four point sensing structure (Booth and Kim, 2012). However, the electrodes covered about $75 \%$ of the culture surface, limiting the optical accessibility and thus the real-time monitoring of cell constructs.

When designing an organ-on-a-chip model of the BBB with both a vascular and parenchymal compartment, assembly is a critical step. In fact, the membrane needs to be seeded on both sides and turned upside down after the first seeding. Brown et al. have reported an interesting solution to tackle this challenge in a complex device, based on the co-culture of four cell populations and equipped with independent inlets and outlets to perfuse the chambers with different media. Their microfluidic chip was composed of three PDMS layers with a $0.2 \mu \mathrm{m}$ polycarbonate membrane dividing the first PDMS sheet from the others. In the first PDMS layer, they have plated primary human brain-derived microvascular EC on the bottom of the membrane and perfused with their medium. Twelve days later, they have turned upside down the device and plated primary astrocytes and pericytes on 
the other side of the membrane. To avoid the overturning of the inlet and outlet tanks when changing the orientation, they have equipped the device with a flippable backpack. Two days later, they have added cortical glutamatergic neurons from hiPSs in the third PDMS substrate. A further feature of interest of this model is the fact that the Authors have embedded the neurons in a $3 \mathrm{D}$ collagen hydrogel to mimic the ECM (Brown et al., 2015).

Adriani et al. have removed the microporous membrane and started from the importance of a 3D matrix mimicking brain ECM. They have proposed a model of the NVU based on a single layer device composed of four parallel PDMS channels. The first channel hosted only medium, the second channel cortical neurons embedded in a collagen hydrogel, the third channel primary astrocytes embedded in a different collagen hydrogel and the last one EC. Each channel communicated directly with the adjacent one, allowing direct cell-cell contact and signaling (Adriani et al., 2017).

In their NVU platform for drug screening applications, Bang et al. have designed separated microchannels to supply different culture media to the cells. Their vascular channel connected to the inner lumen of the vascular network (hosting human fibroblasts and human umbilical vein EC), while the neural channel perfused rat cortical neurons adherent to the vascular network. The Authors have observed a good agreement between the permeability coefficients obtained by 20 and $70 \mathrm{kDa}$ FITCdextran in their NVU and in vivo, suggesting that the use of umbilical cord ECs instead of brain-derived ECs is not a limitation (Bang et al., 2017).

Similarly to Adriani et al., Campisi et al. have highlighted the importance of a 3D matrix mimicking the ECM, but they have also focused on culturing human brain cells to remove crossspecies incompatibility and achieve physiologically relevant results. They have filled the ports of their chip with a fibrin hydrogel embedding the co-culture of hiPS-EC, pericytes and astrocytes from human brains and pipetted hiPSC-EC into the channels. The results have suggested that their model shows physiologically relevant structures and is suitable for several applications, such as the study of the neurovascular function, transport across the $\mathrm{BBB}$ and metastatic cancer extravasation to the brain (Campisi et al., 2018).

\section{GENERAL CONSIDERATIONS AND CHALLENGES FOR THE MGBA IN VITRO MODELING}

Information about the MGBA has mainly come from in vivo studies on GF and SPF mice. Animal models are suitable to reproduce all the communication pathways involved, but they may differ from humans. Moreover, they exhibit high variability (e.g., in SPF mice the excluded mouse pathogens depend on breeding conditions, Hirayama et al., 1990) and the isolation of a single parameter leading to alterations in the gut microbiota or brain homeostasis is difficult. They also pose ethical and economic issues (Dobson et al., 2019).

In accordance with the 3 Rs principle (Replacement, Reduction and Refinement) (Cronin, 2017), in vitro models represent a strategy to overcome these limitations and recapitulate fundamental disease mechanisms. Since they are based on a more controllable and reproducible experimental setup, they offer the possibility to isolate and test different parameters. However, their simplicity with respect to the complexity of the real in vivo situation limits their effective applicability to the study of the MGBA (Cryan et al., 2019).

2D cultures on plastic surfaces are valuable tools for cellbased studies because of their cost-effectiveness, ease of handling and robustness across different cell types. They allow the diffusion of secreted soluble factors in the medium, but they force cell attachment in a planar direction and prevent cellcell and cell-ECM interactions, thus affecting proliferation rate and differentiation. In their physiological microenvironment, cells are surrounded by their own 3D matrix; moreover, they are exposed to endocrine signals from distant tissues, paracrine signals from nearby cells and physical stimuli (e.g., shear stress and oxygen tension). In 2D cultures, we lack most of this biological, mechanical and topographical complexity (Paşca, 2018). Assembloids (Paşca, 2018) rely on the controlled assembly of $3 \mathrm{D}$ cultures to recapitulate more complex cell-cell interactions (e.g., by mixing cells of different lineages or adding cells and biomaterials with organizer-like capabilities), leading to models with improved tissue architecture and reproducibility. To this purpose, hydrogels are promising tools because of their tunable properties, and bioprinting offers a noteworthy contribution to fabricate $3 \mathrm{D}$ living constructs with superior spatial resolution and an automatic and exact cell arrangement (Moroni et al., 2018; Zhuang et al., 2018). However, assembloids need improvements to mimic the ECM (e.g., for brain cultures), support cell viability in larger constructs and control dynamic features (e.g., $\mathrm{pH}$ and oxygen levels).

Organs-on-a-chip allow cell culturing in single chambers, promoting their communication by microfluidic channels and controlling the spatial and temporal distribution of their microenvironment. They offer the possibility to establish more complex, physiologically-relevant and reliable conditions by creating gradients, setting the medium flow to ensure the exchange of nutrients and metabolites and stimulate cell growth, proliferation and differentiation, applying mechanical forces to mimic the physical microenvironment of living organs (e.g., peristalsis-like deformations in the gut), and monitoring the operating parameters (e.g., oxygen, glucose concentration and pH) (Bhatia and Ingber, 2014; Ingber, 2016). In particular, the miniaturization reduces the reagent volumes, while the integration of electronic sensors allows measuring biological and physical parameters (e.g., trans-endothelial/trans-epithelial electrical resistance, usually referred to as TEER, a key parameter to evaluate the integrity of physiological barriers, such as the BBB and the gut epithelium). Since they are miniaturized models of the major functional units of whole organs, the use of organs-ona-chip is currently a very promising strategy to model the MGBA in vitro.

By the combination of physiologically-relevant conditions and cutting-edge technological devices, organs-on-a-chip (and their connection into multi-organ platforms) hold potential for supporting research aimed at the comprehension of the 
molecular mechanisms underlying disorders involving different organs, exploring frontier hypotheses with a multidisciplinary approach and leading to the development of new therapeutic strategies. For instance, Ingberg's research group has provided crucial results for the study of host-microbiome interactions and the development of microbiome-related therapeutics, probiotics and nutraceuticals. In particular, by a microfluidic device ensuring oxygen gradients, Jalili-Firoozinezhad et al. (2019) have co-cultured aerobic and anaerobic human gut microbiota in contact with human intestinal epithelium and its mucus layer on top.

However, the path to model the entire MGBA with a single multi-organ platform is still long. However, from the previous discussion, it is apparent that interdisciplinary strategies combining bioengineering, biochemistry and medicine and leading to innovative in vitro tools are required to overcome technical and biological limitations, and develop reliable platforms to study the whole MGBA.
To this respect, a contribution may come from bioprinting and its applications. This is a technological approach for the simultaneous incorporation of materials, cells and biologically active factors (e.g., for haptotactic gradients; Ilkhanizadeh et al., 2007) with high spatial control and biomimicry. It is a cuttingedge technology with remarkable potential in the field of biomaterials and $3 \mathrm{D}$ tissue models. It is highly versatile in terms of shape, porosity and control of material interconnectivity, it provides a more automated and defined approach to biomaterialcell interfaces, thus fabricating structures with custom-made architectures and create layered and viable 3D cell constructs. However, it requires the precise control of the rheological properties of the bioinks (Paxton et al., 2017). Because of their ability to retain water, hydrogels are excellent microenvironments for cell culture. For this reason, current bioinks for brain cells are hydrogels, both from natural and synthetic polymers. Natural polymers are usually preferred because of their intrinsic biocompatibility, but they are more difficult to print than
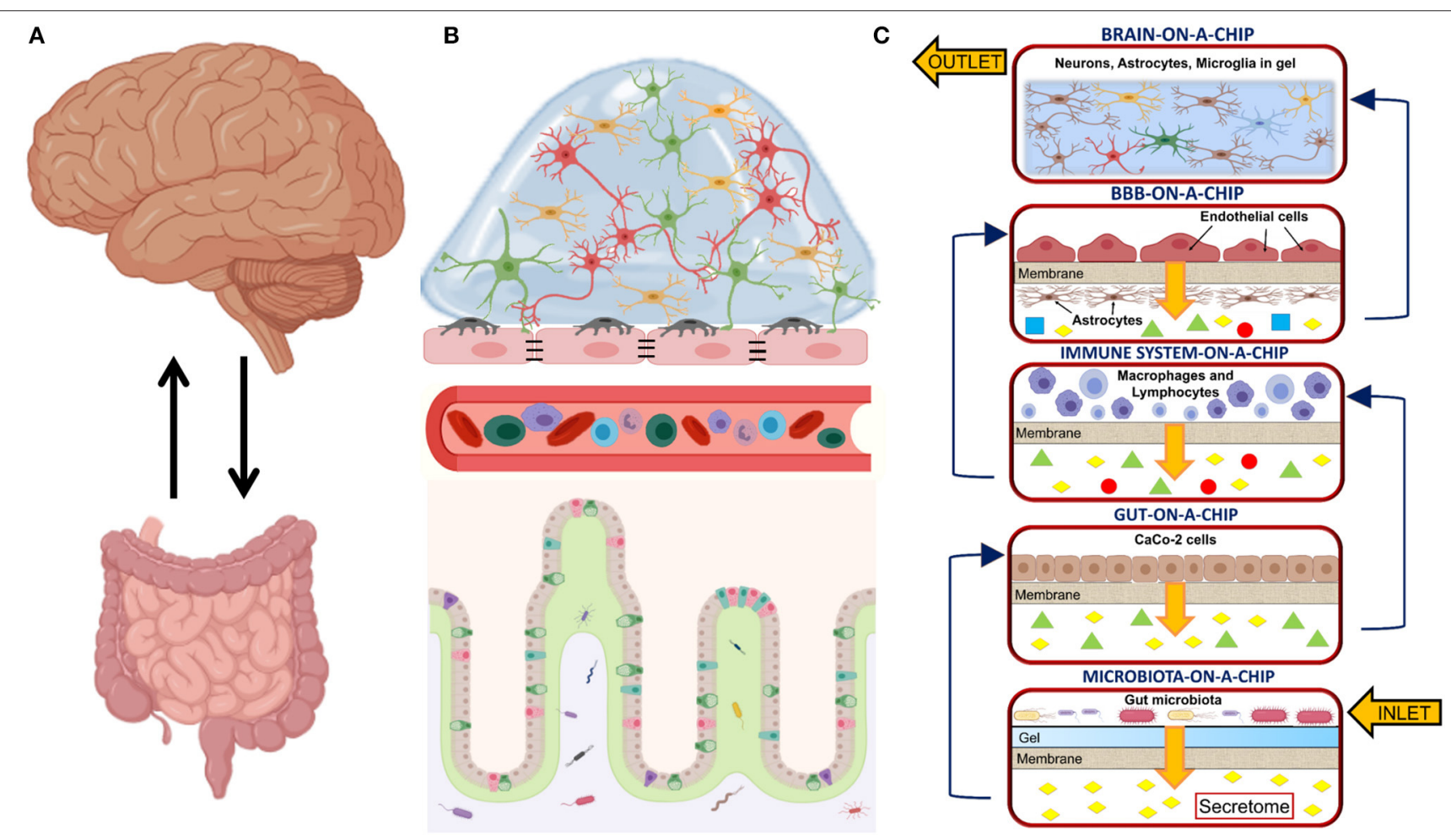

FIGURE 1 | (A) Sketch showing the main organs involved in the microbiota-gut-brain axis and their bidirectional communication; (B) Sketch detailing the biological structures involved in the microbiota-gut-brain axis. From bottom to top: the microbiota resides in the intestinal lumen and in the loose layer of the intestinal mucus. It interplays with the epithelial cells in the gut epithelium, the cells of the immune system circulating into the bloodstream, the blood-brain barrier (BBB) composed of endothelial cells (EC), pericytes and astrocytic end-feet processes and brain cells (e.g., neurons, microglia, astrocytes, and oligodendrocytes); (C) Sketch of the MINERVA organ-on-a-chip platform. From bottom to top: the microbiota-on-a-chip device hosts a microporous membrane supporting a hydrogel-based matrix mimicking gut mucus and inoculated with gut microbiota; the gut-on-a-chip device hosts a microporous membrane seeded with gut epithelial cells (e.g., CaCo-2 cells); the immune system-on-a-chip device hosts macrophages and lymphocytes; the BBB-on-a-chip device hosts two specular monolayers of EC and astrocytes; the brain-on-a-chip device hosts a 3D hydrogel matrix mimicking brain extracellular matrix (ECM) and embedding neurons, microglia and astrocytes. In the MINERVA platform, we have considered two configurations for the brain-on-a-chip device: the first is composed of three chambers hosting the co-culture of neurons, microglia and astrocytes, while the second has three chambers hosting neurons, microglia and astrocytes as a single culture. Both the microbiota and the immune system compartments have filters at the inlet and outlet to prevent cell migrating out from the culture chambers. With the exception of the brain device, each compartment has a microporous membrane to support cell adhesion. It also allows the passage of secretome to the lower part of the culture chamber without mixing of the different culture media. Created with BioRender.com. 
synthetic ones or after printing, their mechanical properties are physiologically irrelevant. Further challenges concern the fact that cell density may influence the final properties of the constructs and stress occurring during printing may affect cell survival and behavior (Moroni et al., 2018; Zhuang et al., 2018).

Despite these limitations, the integration of biomaterials and bioprinting in organs-on-a-chip modeling the brain and the BBB (and, more in general, in in vitro tissue models and disease models) would add complexity to recreate the microenvironment by mimicking the composition and anatomical properties of the ECM and providing key mechanical, biochemical and topographical cues as gradients or localized hotspots (Wolf et al., 2019). The relevance of these benefits has strongly emerged in research fields where the development of vascularized structures is of pivotal importance, like cancer research. For instance, a high degree of vascularization is a pathological hallmark of malignant gliomas and cancer cells migrate through microvessels. In this context, the development of more complex and representative tumor-vascular niches would help to assess cell-cell and cell-ECM interactions, model clinically-relevant phenomena (e.g., patientspecific resistance to chemoradiotherapy; Yi et al., 2019) and suggest innovative therapeutic strategies.

The coupling of bioprinting to microfluidics might also drive the development of automated devices for drug screening and toxicity testing. In this context, bioprinting would allow for a rapid fabrication of hydrogel-based cell-embedding constructs with highly controllable and reproducible thickness. This would lead to consistent diffusion across the hydrogel matrix, with more reproducible results across different experiments (Bhise et al., 2016).

Coming back to the issue of modeling the whole MGBA, we would like to bring to attention that recently the European Research Council has funded a project named MINERVA (ID 724734). It aims at applying a bioengineering approach to the MGBA, by developing technological platforms to elucidate the effect of microbiota secretome on brain functions, in a context of AD-related neurodegeneration. The engineered platform will be suitable not only to study the MGBA, but also to examine other pathologies involving several organs.

The main challenge of the MINERVA project lies in the great complexity arising from the involvement of many biochemical pathways, multi-organ functions and crosstalks. Five optically accessible, microfluidic organs-on-a-chip will compose the final platform. They will model the microbiota, the gut, the immune system, the BBB, and the brain compartment. Each compartment

\section{REFERENCES}

Abbott, N. J., Dolman, D. E., Drndarski, S., and Fredriksson, S.M. (2012). An improved in vitro blood-brain barrier model: rat brain endothelial cells co-cultured with astrocytes. Methods Mol. Biol. 814, 415-430. doi: 10.1007/978-1-61779-452-0_28

Adams, B., Nunes, J. M., Page, M. J., Roberts, T., Carr, J., and Nell, T. A. (2019). Parkinson's disease: a systemic inflammatory disease accompanied by bacterial inflammagens. Front. Aging Neurosci. 11:210. doi: 10.3389/fnagi.2019.00210

Adriani, G., Ma, D., Pavesi, A., Kamm, R. D., and Goh, E. L. (2017). A 3D neurovascular microfluidic model consisting of neurons, astrocytes and will permit both sampling and cell perfusion. A microporous membrane will divide each chamber into two parts, separating the cells from culture medium flowing to the next device. Therefore, before reaching brain cells, culture medium will be enriched with secretome from the gut microbiota, gut epithelial cells, immune cells and BBB cells (Figure 1). A hydrogel matrix simulating the intestinal mucus and hosting the gut microbiota (e.g., from fecal samples from healthy donors or AD patients) will populate the first device and an adjacent flow of medium will collect the secretome. In the following device, gut epithelial cells will be plated on the microporous membrane to model the gut barrier. The next device will host both lymphocytes and macrophages to model the immune system and a microporous membrane will prevent their exit from the device. To model the BBB, EC and astrocytes will be plated on both sides of a microporous membrane; while the final device will model the brain. A 3D hydrogel modeling brain ECM will embed neurons, astrocytes and microglia (as single cell cultures or as a co-culture. For the design and development of the basic organ-on-a-chip device, MINERVA has started from a miniaturized, optically accessible bioreactor developed for the interstitial perfusion of 3D cell constructs (Izzo et al., 2019) and validated for advanced in vitro cell modeling (Tunesi et al., 2016; Marturano-Kruik et al., 2018). MINERVA may be the first example of a multiorgan platform suitable to face in vitro with a very complex biochemical pathway as the MGBA, paving the way to significant advancements in the field, for example the discovery of new, not invasive therapies for neurodegenerative disorders based on microbiota management by food ingredients or probiotics.

\section{AUTHOR CONTRIBUTIONS}

IR, LI, and MT wrote, reviewed, and edited the original draft. MC reviewed the original draft. DA reviewed and edited the original draft. CG reviewed and edited the manuscript.

\section{FUNDING}

MINERVA project received funding from the European Research Council (ERC) under the European Union's Horizon 2020 research and innovation program (Grant Agreement no. 724734).

\section{ACKNOWLEDGMENTS}

We thank Judith Baggott for English editing. in microbiota-related research. J. Microbiol. Biotechnol. 25, 1583-1588. doi: 10.4014/jmb.1501.01039

Appelt-Menzel, A., Cubukova, A., Günther, K., Edenhofer, F., Piontek, J., Krause, G., et al. (2017). Establishment of a human blood-brain barrier co-culture model mimicking the neurovascular unit using induced pluri- and multipotent stem cells. Stem Cell Rep. 8, 894-906. doi: 10.1016/j.stemcr.2017.02.021

Arriagada, P. V., Growdon, J. H., Hedley-Whyte, E. T., and Hyman, B. T. (1992). Neurofibrillary tangles but not senile plaques parallel duration and severity 
of Alzheimer's disease. Neurology 42(3 Pt 1), 631-639. doi: 10.1212/WNL. 42.3 .631

Asti, A., and Gioglio, L. (2014). Can a bacterial endotoxin be a key factor in the kinetics of amyloid fibril formation? J. Alzheimers. Dis. 39, 169-179. doi: 10.3233/JAD-131394

Baganz, N. L., and Blakely, R. D. (2013). A dialogue between the immune system and brain, spoken in the language of serotonin. ACS Chem. Neurosci. 4, 48-63. doi: $10.1021 / \mathrm{cn} 300186 \mathrm{~b}$

Banerjee, J., Shi, Y., and Azevedo, H. S. (2016). In vitro blood-brain barrier models for drug research: state-of-the-art and new perspectives on reconstituting these models on artificial basement membrane platforms. Drug Discov. Today. 21, 1367-1386. doi: 10.1016/j.drudis.2016.05.020

Bang, S., Lee, S. R., Ko, J., Son, K., Tahk, D., Ahn, J., et al. (2017). A low permeability microfluidic blood-brain barrier platform with direct contact between perfusable vascular network and astrocytes. Sci. Rep. 7:8083. doi: 10.1038/s41598-017-07416-0

Bardell, D. (1983). The roles of the sense of taste and clean teeth in the discovery of bacteria by Antoni van Leeuwenhoek. Microbiol Rev. 47, 121-126.

Barnard, J. A., and Warwick, G. A. (1993). Butyrate rapidly induces growth inhibition and differentiation in HT-29 cells. Cell Growth Differ. 4, 495-501.

Barrett, E., Ross, R. P., O’Toole, P. W., Fitzgerald, G. F., and Stanton, C. (2012). $\gamma$ Aminobutyric acid production by culturable bacteria from the human intestine. J. Appl. Microbiol. 113, 411-417. doi: 10.1111/j.1365-2672.2012.05344.x

Bhatia, S. N., and Ingber, D. E. (2014). Microfluidic organ-on-a-chips. Nat. Biotechnol. 32, 760-772. doi: 10.1038/nbt.2989

Bhattacharjee, S., and Lukiw, W. J. (2013). Alzheimer's disease and the microbiome. Front. Cell. Neurosci. 7:153. doi: 10.3389/fncel.2013.00153

Bhise, N. S., Manoharan, V., Massa, S., Tamayol, A., Ghaderi, M., Miscuglio, M., et al. (2016). A liver-on-a-chip platform with bioprinted hepatic spheroids. Biofabrication. 8:014101. doi: 10.1088/1758-5090/8/1/014101

Bickel, U. (2005). How to measure drug transport across the blood-brain barrier. NeuroRx. 2, 15-26. doi: 10.1602/neurorx.2.1.15

Biedermann, L., Zeitz, J., Mwinyi, J., Sutter-Minder, E., Rehman, A., Ott, S. J., et al. (2013). Smoking cessation induces profound changes in the composition of the intestinal microbiota in humans. PLoS ONE 8:e59260. doi: 10.1371/journal.pone.0059260

Bonaz, B., Bazin, B., and Pellissier, S. (2018). The vagus nerve at the interface of the microbiota-gut-brain axis. Front. Neurosci. 12:49. doi: 10.3389/fnins.2018.00049

Bonaz, B., Picq, C., Sinniger, V., Mayol, J. F., and Clarençon, D. (2013). Vagus nerve stimulation: from epilepsy to the cholinergic anti-inflammatory pathway. Neurogastroenterol. Motil. 25, 208-221. doi: 10.1111/nmo.12076

Booth, R., and Kim, H. (2012). Characterization of a microfluidic in vitro model of the blood-brain barrier ( $\mu$ BBB). Lab Chip. 12, 1784-1792. doi: 10.1039/c2lc40094d

Borre, Y. E., Moloney, R. D., Clarke, G., Dinan, T. G., and Cryan, J. F. (2014). The impact of microbiota on brain and behavior: mechanisms \& therapeutic potential. Adv. Exp. Med. Biol. 817, 373-403. doi: 10.1007/978-1-4939-0897-4_17

Bors, L. A., and Erdö, F. (2019). Overcoming the blood-brain barrier. Challenges and tricks for CNS drug delivery. Sci. Pharm. 87:6. doi: 10.3390/scipharm87010006

Bourassa, M. W., Alim, I., Bultman, S. J., and Ratan, R. R. (2016). Butyrate, neuroepigenetics and the gut microbiome: can a high fiber diet improve brain health? Neurosci. Lett. 625, 56-63. doi: 10.1016/j.neulet.2016. 02.009

Boyer-Di Ponio, J., El-Ayoubi, F., Glacial, F., Ganeshamoorthy, K., Driancourt, C., Godet, M., et al. (2014). Instruction of circulating endothelial progenitors in vitro towards specialized blood-brain barrier and arterial phenotypes. PLoS ONE 9:e84179. doi: 10.1371/journal.pone.0084179

Braak, H., de Vos, R. A., Bohl, J., and Del Tredici, K. (2006). Gastric alphasynuclein immunoreactive inclusions in Meissner's and Auerbach's plexuses in cases staged for Parkinson's disease-related brain pathology. Neurosci. Lett. 396, 67-72. doi: 10.1016/j.neulet.2005.11.012

Braniste, V., Al-Asmakh, M., Kowal, C., Anuar, F., Abbaspour, A., Tóth, M., et al. (2014). The gut microbiota influences blood-brain barrier permeability in mice. Sci. Transl. Med. 6:263ra158. doi: 10.1126/scitranslmed. 3009759
Bravo, J. A., Forsythe, P., Chew, M. W., Escaravage, E., Savignac, H. M., Dinan, T. G., et al. (2011). Ingestion of Lactobacillus strain regulates emotional behavior and central GABA receptor expression in a mouse via the vagus nerve. Proc. Natl. Acad. Sci. U.S.A. 108, 16050-16055. doi: 10.1073/pnas.1102999108

Brenner, S. R. (2013). Blue-green algae or cyanobacteria in the intestinal micro-flora may produce neurotoxins such as Beta-N-Methylamino-L-Alanine (BMAA) which may be related to development of amyotrophic lateral sclerosis, Alzheimer's disease and Parkinson-Dementia-Complex in humans and Equine Motor Neuron Disease in horses. Med. Hypotheses. 80:103. doi: 10.1016/j.mehy.2012.10.010

Brown, J. A., Pensabene, V., Markov, D. A., Allwardt, V., Neely, M. D., Shi, M., et al. (2015). Recreating blood-brain barrier physiology and structure on chip: A novel neurovascular microfluidic bioreactor. Biomicrofluidics. 9:054124. doi: $10.1063 / 1.4934713$

Butt, H. J., Wolff, E. K., Gould, S. A., Dixon Northern, B., Peterson, C. M., and Hansma, P. K. (1990). Imaging cells with the atomic force microscope. J. Struct. Biol. 105, 54-61. doi: 10.1016/1047-8477(90)90098-W

Campisi, M., Shin, Y., Osaki, T., Hajal, C., Chiono, V., and Kamm, R. D. (2018). 3D self-organized microvascular model of the human blood-brain barrier with endothelial cells, pericytes and astrocytes. Biomaterials 180, 117-129. doi: 10.1016/j.biomaterials.2018.07.014

Cantrill, C. A., Skinner, R. A., Rothwell, N. J., and Penny, J. I. (2012). An immortalised astrocyte cell line maintains the in vivo phenotype of a primary porcine in vitro blood-brain barrier model. Brain Res. 1479, 17-30. doi: 10.1016/j.brainres.2012.08.031

Carabotti, M., Scirocco, A., Maselli, M. A., and Severi, C. (2015). The gut-brain axis: interactions between enteric microbiota, central and enteric nervous systems. Ann Gastroenterol. 28, 203-209.

Cecchelli, R., Dehouck, B., Descamps, L., Fenart, L., Buée-Scherrer, V., Duhem, C., et al. (1999). In vitro model for evaluating drug transport across the blood-brain barrier. Adv. Drug Deliv. Rev. 36, 165-178. doi: 10.1016/s0169-409x(98)00083-0

Cekanaviciute, E., Yoo, B. B., Runia, T. F., Debelius, J. W., Singh, S., and Nelson, C. A. (2017). Gut bacteria from multiple sclerosis patients modulate human T cells and exacerbate symptoms in mouse models. Proc. Natl. Acad. Sci. U.S.A. 114, 10713-10718. doi: 10.1073/pnas.1711235114

Clarke, G., Grenham, S., Scully, P., Fitzgerald, P., Moloney, R. D., Shanahan, F., et al. (2013). The microbiome-gut-brain axis during early life regulates the hippocampal serotonergic system in a sex-dependent manner. Mol. Psychiatry. 18, 666-673. doi: 10.1038/mp.2012.77

Cohen-Kashi Malina, K., Cooper, I., and Teichberg, V. I. (2009). Closing the gap between the in-vivo and in-vitro blood-brain barrier tightness. Brain Res. 1284, 12-21. doi: 10.1016/j.brainres.2009.05.072

Coisne, C., Dehouck, L., Faveeuw, C., Delplace, Y., Miller, F., Landry, C., et al. (2005). Mouse syngenic in vitro blood-brain barrier model: a new tool to examine inflammatory events in cerebral endothelium. Lab. Invest. 85, 734-746. doi: 10.1038/labinvest.3700281

Collins, J., Borojevic, R., Verdu, E. F., Huizinga, J. D., and Ratcliffe, E. M. (2014). Intestinal microbiota influence the early postnatal development of the enteric nervous system. Neurogastroenterol. Motil. 26, 98-107. doi: 10.1111/nmo.12236

Crone, C., and Olesen, S. P. (1982). Electrical resistance of brain microvascular endothelium. Brain Res. 241, 49-55. doi: 10.1016/0006-8993(82)91227-6

Cronin, M. T. (2017). "Non-animal approaches, the way forward," in European Commission Scientific Conference (Brussels).

Cryan, J. F., O’ Riordan, K. J., Cowan, C. S. M., Sandhu, K. V., Bastiaanssen, T. F. S., Boehme, M., et al. (2019). The microbiota-gut-brain axis. Physiol. Rev. 99, 1877-2013. doi: 10.1152/physrev.00018.2018

Dai, X., Ma, C., Lan, Q., and Xu, T. (2016). 3D bioprinted glioma stem cells for brain tumor model and applications of drug susceptibility. Biofabrication 8:045005. doi: 10.1088/1758-5090/8/4/045005

Dando, S. J., Mackay-Sim, A., Norton, R., Currie, B. J., St. John, J. A., Ekberg, J. A., et al. (2014). Pathogens penetrating the central nervous system: infection pathways and the cellular and molecular mechanisms of invasion. Clin. Microbiol. Rev. 27, 691-726. doi: 10.1128/CMR.00118-13

Dantzer, R. (2018). Neuroimmune interactions: from the brain to the immune system and vice versa. Physiol. Rev. 98, 477-504. doi: 10.1152/physrev.00039.2016

Dauer, W., and Przedborski, S. (2003). Parkinson's disease: mechanisms and models. Neuron 39, 889-909. doi: 10.1016/S0896-6273(03)00568-3 
Daulatzai, M. A. (2014). Role of stress, depression, and aging in cognitive decline and Alzheimer's disease. Curr. Top. Behav. Neurosci. 18, 265-296. doi: 10.1007/7854_2014_350

De Caro, C., Iannone, L. F., Citraro, R., Striano, P., De Sarro, G., Constanti, A., et al. (2019b). Can we 'seize' the gut microbiota to treat epilepsy? Neurosci. Biobehav. Rev. 107, 750-764. doi: 10.1016/j.neubiorev.2019.10.002

De Caro, C., Leo, C., Nesci, V., Ghelardini, C., di Cesare Mannelli, L., Striano, P., et al. (2019a). Intestinal inflammation increases convulsant activity and reduces antiepileptic drug efficacy in a mouse model of epilepsy. Sci. Rep. 9:13983. doi: 10.1038/s41598-019-50542-0

De Punder, K., and Pruimboom, L. (2015). Stress induces endotoxemia and lowgrade inflammation by increasing barrier permeability. Front. Immunol. 6:223. doi: 10.3389/fimmu.2015.00223

De Vadder, F., Grasset, E., Mannerås Holm, L., Karsenty, G., and Macpherson, A. J., Olofsson, L. E., et al. (2018). Gut microbiota regulates maturation of the adult enteric nervous system via enteric serotonin networks. Proc. Natl. Acad. Sci. U.S.A. 115, 6458-6463. doi: 10.1073/pnas.1720017115

Dehouck, M. P., Méresse, S., Delorme, P., Fruchart, J. C., and Cecchelli, R. (1990). An easier, reproducible, and mass-production method to study the blood-brain barrier in vitro. J. Neurochem. 54, 1798-1801. doi: 10.1111/j.1471-4159.1990.tb01236.x

Delcourt, N., Claudepierre, T., Maignien, T., Arnich, N., and Mattei, C. (2017). Cellular and molecular aspects of the $\beta$-N-methylamino-l-alanine (BMAA) mode of action within the neurodegenerative pathway: facts and controversy. Toxins 10:6. doi: 10.3390/toxins10010006

Di Meo, F., Donato, S., Di Pardo, A., Maglione, V., Filosa, S., and Crispi, S. (2018). New therapeutic drugs from bioactive natural molecules: the role of gut microbiota metabolism in neurodegenerative diseases. Curr. Drug Metab. 19, 478-489. doi: 10.2174/1389200219666180404094147

Dinan, T. G., and Cryan, J. F. (2017). Brain-gut-microbiota axis and mental health. Psychosom. Med. 79, 920-926. doi: 10.1097/PSY.0000000000 000519

Dingle, Y. T., Boutin, M. E., Chirila, A. M., Livi, L. L., Labriola, N. R., Jakubek, L. M., et al. (2015). Three-dimensional neural spheroid culture: an in vitro model for cortical studies. Tissue Eng. Part C Methods. 21, 1274-1283. doi: 10.1089/ten.tec.2015.0135

Dobson, G., Letson, H., Biros, E., and Morris, J. (2019). Specific pathogen-free (SPF) animal status as a variable in biomedical research: have we come full circle? EBioMed. 41, 42-43. doi: 10.1016/j.ebiom.2019.02.038

Dominy, S. S., Lynch, C., Ermini, F., Benedyk, M., Marczyk, A., Konradi, A., et al. (2019). Porphyromonas gingivalis in Alzheimer's disease brains: evidence for disease causation and treatment with small-molecule inhibitors. Sci. Adv. 5:eaau3333. doi: 10.1126/sciadv.aau3333

El Aidy, S., Dinan, T. G., and Cryan, J. F. (2015). Gut microbiota: the conductor in the orchestra of immune-neuroendocrine communication. Clin. Ther. 37, 954-967. doi: 10.1016/j.clinthera.2015.03.002

Erny, D., Hrabě de Angelis, A. L., Jaitin, D., Wieghofer, P., Staszewski, O., David, E., et al. (2015). Host microbiota constantly control maturation and function of microglia in the CNS. Nat. Neurosci. 18, 965-977. doi: 10.1038/nn.4030

Farzi, A., Fröhlich, E. E., and Holzer, P. (2018). Gut microbiota and the neuroendocrine system. Neurotherapeutics 15, 5-22. doi: 10.1007/s13311-017-0600-5

Fennema, E., Rivron, N., Rouwkema, J., van Blitterswijk, C., and de Boer, J. (2013). Spheroid culture as a tool for creating 3D complex tissues. Trends Biotechnol. 31, 108-115. doi: 10.1016/j.tibtech.2012.12.003

Finnie, I. A., Dwarakanath, A. D., Taylor, B. A., and Rhodes, J. M. (1995). Colonic mucin synthesis is increased by sodium butyrate. Gut 36, 93-99. doi: 10.1136/gut.36.1.93

Forsyth, C. B., Shannon, K. M., Kordower, J. H., Voigt, R. M., Shaikh, M., Jaglin, J. A., et al. (2011). Increased intestinal permeability correlates with sigmoid mucosa alpha-synuclein staining and endotoxin exposure markers in early Parkinson's disease. PLoS ONE 6:e28032. doi: 10.1371/journal.pone.0028032

Foster, J. A., and McVey Neufeld, K. A. (2013). Gut-brain axis: how the microbiome influences anxiety and depression. Trends Neurosci. 36, 305-312. doi: 10.1016/j.tins.2013.01.005

Foster, J. A., Rinaman, L., and Cryan, J. F. (2017). Stress \& the gutbrain axis: regulation by the microbiome. Neurobiol. Stress 7, 124-136. doi: 10.1016/j.ynstr.2017.03.001
Fung, T. C., Olson, C. A., and Hsiao, E. Y. (2017). Interactions between the microbiota, immune and nervous systems in health and disease. Nat. Neurosci. 20, 145-155. doi: 10.1038/nn.4476

Furusawa, Y., Obata, Y., Fukuda, S., Endo, T. A., Nakato, G., Takahashi, D., et al. (2013). Commensal microbe-derived butyrate induces the differentiation of colonic regulatory T cells. Nature 504, 446-450. doi: 10.1038/nature 12721

Gaillard, P. J., van der Sandt, I. C., Voorwinden, L. H., Vu, D., Nielsen, J. L., de Boer, A. G., et al. (2000). Astrocytes increase the functional expression of Pglycoprotein in an in vitro model of the blood-brain barrier. Pharm. Res. 17, 1198-1205. doi: 10.1023/A:1026406528530

Gaillard, P. J., Voorwinden, L. H., Nielsen, J. L., Ivanov, A., Atsumi, R., Engman, H., et al. (2001). Establishment and functional characterization of an in vitro model of the blood-brain barrier, comprising a co-culture of brain capillary endothelial cells and astrocytes. Eur. J. Pharm. Sci. 12, 215-222. doi: 10.1016/S0928-0987(00)00123-8

Gelpi, E., Navarro-Otano, J., Tolosa, E., Gaig, C., Compta, Y., Rey, M. J., et al. (2014). Multiple organ involvement by alpha-synuclein pathology in Lewy body disorders. Mov. Disord. 29, 1010-1018. doi: 10.1002/mds.25776

Gold, A., Turkalp, Z. T., and Munoz, D. G. (2013). Enteric alpha-synuclein expression is increased in Parkinson's disease but not Alzheimer's disease. Mov. Disord. 28, 237-240. doi: 10.1002/mds.25298

Grenham, S., Clarke, G., Cryan, J. F., and Dinan, T. G. (2011). Braingut-microbe communication in health and disease. Front. Physiol. 2:94. doi: 10.3389/fphys.2011.00094

Grider, J. R., and Piland, B. E. (2007). The peristaltic reflex induced by shortchain fatty acids is mediated by sequential release of 5-HT and neuronal CGRP but not BDNF. Am. J. Physiol. Gastrointest. Liver Physiol. 292, G429-G437. doi: 10.1152/ajpgi.00376.2006

Griep, L. M., Wolbers, F., de Wagenaar, B., ter Braak, P. M., Weksler, B. B., Romero, I. A., et al. (2013). BBB on chip: microfluidic platform to mechanically and biochemically modulate blood-brain barrier function. Biomed. Microdevices 15, 145-150. doi: 10.1007/s10544-012-9699-7

Groschwitz, K. R., and Hogan, S. P. (2009). Intestinal barrier function: molecular regulation and disease pathogenesis. J. Allergy Clin. Immunol. 124, 3-20; quiz 21-22. doi: 10.1016/j.jaci.2009.05.038

Gu, Q., Tomaskovic-Crook, E., Lozano, R., Chen, Y., Kapsa, R. M., Zhou, Q., et al. (2016). Functional 3D neural mini-tissues from printed gel-based bioink and human neural stem cells. Adv. Healthc. Mater. 5, 1429-1438. doi: 10.1002/adhm.201600095

Guaní-Guerra, E., Santos-Mendoza, T., Lugo-Reyes, S. O., and Terán, L. M. (2010). Antimicrobial peptides: general overview and clinical implications in human health and disease. Clin. Immunol. 135, 1-11. doi: 10.1016/j.clim.2009.12.004

Harach, T., Marungruang, N., Duthilleul, N., Cheatham, V., Mc Coy, K. D., Frisoni, G., et al. (2017). Erratum: reduction of abeta amyloid pathology in APPPS1 transgenic mice in the absence of gut microbiota. Sci. Rep. 7:46856. doi: $10.1038 /$ srep 46856

Hasan, M. F., and Berdichevsky, Y. (2016). Neural circuits on a chip. Micromachines 7:157. doi: 10.3390/mi7090157

Helms, H. C., Abbott, N. J., Burek, M., Cecchelli, R., Couraud, P. O., Deli, M. A., et al. (2016). In vitro models of the blood-brain barrier: an overview of commonly used brain endothelial cell culture models and guidelines for their use. J. Cereb. Blood Flow Metab. 36, 862-890. doi: 10.1177/0271678X1 6630991

Helms, H. C., and Brodin, B. (2014). Generation of primary cultures of bovine brain endothelial cells and setup of cocultures with rat astrocytes. Methods Mol. Biol. 1135, 365-382. doi: 10.1007/978-1-4939-0320-7_30

Helms, H. C., Waagepetersen, H. S., Nielsen, C. U., and Brodin, B. (2010). Paracellular tightness and claudin-5 expression is increased in the BCEC/astrocyte blood-brain barrier model by increasing media buffer capacity during growth. AAPS J. 12, 759-770. doi: 10.1208/s12248-010-9237-6

Hirayama, K., Endo, K., Kawamura, S., and Mitsuoka, T. (1990). Comparison of the intestinal bacteria in specific pathogen free mice from different breeders. Jikken Dobutsu 39, 263-267. doi: 10.1538/expanim1978.39.2_263

Ho, L., Ono, K., Tsuji, M., Mazzola, P., Singh, R., and Pasinetti, G. M. (2018). Protective roles of intestinal microbiota derived short chain fatty acids in Alzheimer's disease-type beta-amyloid neuropathological mechanisms. Expert Rev. Neurother. 18, 83-90. doi: 10.1080/14737175.2018.1400909 
Hoban, D. B., Connaughton, E., Connaughton, C., Hogan, G., Thornton, C., Mulcahy, P, et al. (2013). Further characterisation of the LPS model of Parkinson's disease: a comparison of intra-nigral and intra-striatal lipopolysaccharide administration on motor function, microgliosis and nigrostriatal neurodegeneration in the rat. Brain Behav. Immun. 27, 91-100. doi: 10.1016/j.bbi.2012.10.001

Holzer, P., and Farzi, A. (2014). Neuropeptides and the microbiota-gut-brain axis. Adv. Exp. Med. Biol. 817, 195-219. doi: 10.1007/978-1-4939-0897-4_9

Hopkins, A. M., DeSimone, E., Chwalek, K., and Kaplan, D. L. (2015). 3D in vitro modeling of the central nervous system. Sci. China Life Sci. 59, 1006-1023. doi: 10.1016/j.pneurobio.2014.11.003

Hosseinichimeh, N., Rahmandad, H., and Wittenborn, A. K. (2015). Modeling the hypothalamus-pituitary-adrenal axis: a review and extension. Math. Biosci. 268, 52-65. doi: 10.1016/j.mbs.2015.08.004

Hsieh, F. Y., Lin, H. H., and Hsu, S. H. (2015). 3D bioprinting of neural stem cell-laden thermoresponsive biodegradable polyurethane hydrogel and potential in central nervous system repair. Biomaterials 71, 48-57. doi: 10.1016/j.biomaterials.2015.08.028

$\mathrm{Hu}, \mathrm{X}$., Wang, T., and Jin, F. (2016). Alzheimer's disease and gut microbiota. Sci. China Life Sci. 59, 1006-1023. doi: 10.1007/s11427-016-5083-9

Hyland, N. P., and Cryan, J. F. (2016). Microbe-host interactions: influence of the gut microbiota on the enteric nervous system. Dev. Biol. 417, 182-187. doi: 10.1016/j.ydbio.2016.06.027

Iannone, L. F., Belcastro, V., Verrotti, A., Russo, E., and Striano, P. (2019). Gut microbiota and psychogenic non-epileptic seizures: I can feel it in the belly. Expert Rev. Neurother. 19:1165. doi: 10.1080/14737175.2019.1684901

Ilkhanizadeh, S., Teixeira, A. I., and Hermanson, O. (2007). Inkjet printing of macromolecules on hydrogels to steer neural stem cell differentiation. Biomaterials 28, 3936-3943. doi: 10.1016/j.biomaterials.2007.05.018

Ingber, D. E. (2016). Reverse engineering human pathophysiology with organ-ona-chips. Cell 164, 1105-1109. doi: 10.1016/j.cell.2016.02.049

Izzo, L., Tunesi, M., Boeri, L., Lagan,à, M., Giordano, C., and Raimondi, M. T. (2019). Influence of the static magnetic field on cell response in a miniaturized optically accessible bioreactor for 3D cell culture. Biomed. Microdevices 21:29. doi: 10.1007/s10544-019-0387-8

Jäckel, S., Kiouptsi, K., Lillich, M., Hendrikx, T., Khandagale, A., Kollar, B., et al. (2017). Gut microbiota regulate hepatic von Willebrand factor synthesis and arterial thrombus formation via Toll-like receptor-2. Blood 130, 542-553. doi: 10.1182/blood-2016-11-754416

Jalili-Firoozinezhad, S., Gazzaniga, F. S., Calamari, E. L., Camacho, D. M., Fadel, C. W., Bein, A., et al. (2019). A complex human gut microbiome cultured in an anaerobic intestine-on-a-chip. Nat. Biomed. Eng. 3, 520-531. doi: 10.1038/s41551-019-0397-0

Jia, W., Li, H., Zhao, L., and Nicholson, J. K. (2008). Gut microbiota: a potential new territory for drug targeting. Nat. Rev. Drug Discov. 7, 123-129. doi: $10.1038 / \mathrm{nrd} 2505$

Jiang, H., Ling, Z., Zhang, Y., Mao, H., Ma, Z., Yin, Y., et al. (2015). Altered fecal microbiota composition in patients with major depressive disorder. Brain Behav. Immun. 48, 186-194. doi: 10.1016/j.bbi.2015.03.016

Jiang, L., Li, S., Zheng, J., Li, Y., and Huang, H. (2019). Recent progress in microfluidic models of the blood-brain barrier. Micromachines 10:375. doi: $10.3390 / \mathrm{mi} 10060375$

Kandel, E. R., Schwartz, J. H., and Jassell, T. M. (2012). Principles of Neural Science, 5th Edn. 1760.

Karlsson, O., Jiang, L., Andersson, M., Ilag, L. L., and Rittebo, E. B. (2014). Protein association of the neurotoxin and non-protein amino acid BMAA $(\beta$-N-methylamino-L-alanine) in the liver and brain following neonatal administration in rats. Toxicol. Lett. 226, 1-5. doi: 10.1016/j.toxlet.2014.01.027

Kilic, O., Pamies, D., Lavell, E., Schiapparelli, P., Feng, Y., Hartung, T., et al. (2016). Brain-on-a-chip model enables analysis of human neuronal differentiation and chemotaxis. Lab Chip. 16, 4152-4162. doi: 10.1039/C6LC00946H

Kim, D. Y., and Camilleri, M. (2000). Serotonin: a mediator of the brain-gut connection. Am. J. Gastroenterol. 95, 2698-2709. doi: 10.1111/j.1572-0241.2000.03177.x

Kim, K. S. (2008). Mechanisms of microbial traversal of the blood-brain barrier. Nat. Rev. Microbiol. 6, 625-634. doi: 10.1038/nrmicro1952

Kinane, J. A., Benakanakere, M. R., Zhao, J., Hosur, K. B., and Kinane, D. F. (2012). Porphyromonas gingivalis influences actin degradation within epithelial cells during invasion and apoptosis. Cell. Microbiol. 14, 1085-1096. doi: 10.1111/j.1462-5822.2012.01780.x

Koo, Y., Hawkins, B. T., and Yun, Y. (2018). Three-dimensional (3D) tetra-culture brain on chip platform for organophosphate toxicity screening. Sci. Rep. 8:2841. doi: 10.1038/s41598-018-20876-2

Kowalski, K., and Mulak, A. (2019). Brain-gut-microbiota axis in Alzheimer's disease. J. Neurogastroenterol. Motil. 25, 48-60. doi: 10.5056/jnm 18087

Kristensson, K. (2011). Microbes' roadmap to neurons. Nat. Rev. Microbiol. 6, 625-634. doi: 10.1038/nrn3029

Lancaster, M. A., Renner, M., Martin, C. A., Wenzel, D., Bicknell, L. S., and Hurles, M. E. (2013). Cerebral organoids model human brain development and microcephaly. Nature 501, 373-379. doi: 10.1038/nature 12517

Landete, J. M., De las Rivas, B., Marcobal, A., and Muñoz, R. (2008). Updated molecular knowledge about histamine biosynthesis by bacteria. Crit. Rev. Food Sci. Nutr. 48, 697-714. doi: 10.1080/10408390701639041

Lee, W., Pinckney, J., Lee, V., Lee, J. H., Fischer, K., and Polio, S. (2009). Three-dimensional bioprinting of rat embryonic neural cells. Neuroreport 20, 798-803. doi: 10.1097/WNR.0b013e32832b8be4

Lerner, A., Neidhöfer, S., Matthias, T. (2017). The gut microbiome feelings of the brain: a perspective for non-microbiologists. Microorganisms 5:E66. doi: 10.3390/microorganisms5040066

Li, Q., and Zhou, J. M. (2016). The microbiota-gut-brain axis and its potential therapeutic role in autism spectrum disorder. Neuroscience 324, 131-139. doi: 10.1016/j.neuroscience.2016.03.013

Lin, C. H., Wang, C. H., Hsu, S. L., Liao, S. Y., Lin, T. S., and Hsueh, C. M. (2016) Molecular mechanisms responsible for neuron-derived conditioned medium (NCM)-mediated protection of ischemic brain. PLoS ONE 11:e0146692. doi: 10.1371/journal.pone.0146692

Lin, Q. (2013). Submerged fermentation of Lactobacillus rhamnosus YS9 for $\gamma$-aminobutyric acid (GABA) production. Braz. J. Microbiol. 44, 183-187. doi: 10.1590/S1517-83822013000100028

Lippmann, E. S., Al-Ahmad, A., Azarin, S. M., Palecek, S. P., and Shusta, E. V. (2014). A retinoic acid-enhanced, multicellular human blood-brain barrier model derived from stem cell sources. Sci. Rep. 4:4160. doi: 10.1038/srep 04160

Lippmann, E. S., Azarin, S. M., Kay, J. E., Nessler, R. A., Wilson, H. K., Al-Ahmad, A., et al. (2012). Derivation of blood-brain barrier endothelial cells from human pluripotent stem cells. Nat. Biotechnol. 30, 783-791. doi: 10.1038/nbt. 2247

Liu, J., Sun, J., Wang, F., Yu, X., Ling, Z., Li, H., et al. (2015). Neuroprotective effects of clostridium butyricum against vascular dementia in mice via metabolic butyrate. Biomed Res. Int. 2015:412946. doi: 10.1155/2015/ 412946

Logsdon, A. F., Erickson, M. A., Rhea, E. M., Salameh, T. S., and Banks, W. A. (2018). Gut reactions: how the blood-brain barrier connects the microbiome and the brain. Exp. Biol. Med. 243, 159-165. doi: 10.1177/1535370217 743766

Lomasney, K. W., Houston, A., Shanahan, F., Dinan, T. G., Cryan, J. F., and Hyland, N. P. (2014). Selective influence of host microbiota on cAMPmediated ion transport in mouse colon. Neurogastroenterol. Motil. 26, 887-890. doi: $10.1111 / \mathrm{nmo} .12328$

Lozano, R., Stevens, L., Thompson, B. C., Gilmore, K. J., Gorkin, R. III, Stewart, E. M., et al. (2015). 3D printing of layered brain-like structures using peptide modified gellan gum substrates. Biomaterials 67, 264-273. doi: 10.1016/j.biomaterials.2015.07.022

Luczynski, P., McVey Neufeld, K. A., Oriach, C. S., Clarke, G., Dinan, T. G., and Cryan, J. F. (2016). Growing up in a bubble: using germ-free animals to assess the influence of the gut microbiota on brain and behavior. Int. J. Neuropsychopharmacol. 19:pyw020. doi: 10.1093/ijnp/pyw020

Lyte, M., Vulchanova, L., and Brown, D. R. (2011). Stress at the intestinal surface: catecholamines and mucosa-bacteria interactions. Cell Tissue Res. 343, 23-32. doi: 10.1007/s00441-010-1050-0

Marsland, A. L., Walsh, C., Lockwood, K., and John-Henderson, N. A. (2017). The effects of acute psychological stress on circulating and stimulated inflammatory markers: a systematic review and meta-analysis. Brain Behav. Immun. 64, 208-219. doi: 10.1016/j.bbi.2017.01.011 
Martin, C. R., Osadchiy, V., Kalani, A., and Mayer, E. A. (2018). The brain-gut-microbiome axis. Cell. Mol. Gastroenterol. Hepatol. 6, 133-148. doi: 10.1016/j.jcmgh.2018.04.003

Marturano-Kruik, A., Nava, M. M., Yeager, K., Chramiec, A., Hao, L., Robinson, S., et al. (2018). Human Bone perivascular niche-on-a-chip for studying metastatic colonization. Proc. Natl. Acad. Sci. U.S.A. 115, 1256-1261. doi: $10.1073 /$ pnas. 1714282115

Matsumoto, M., Kibe, R., Ooga, T., Aiba, Y., Sawaki, E., Koga, Y., et al. (2013). Cerebral low-molecular metabolites influenced by intestinal microbiota: a pilot study. Front. Syst. Neurosci. 7:9. doi: 10.3389/fnsys.2013.00009

Mawe, G. M., and Hoffman, J. M. (2013). Serotonin signalling in the gut-functions, dysfunctions and therapeutic targets. Nat. Rev. Gastroenterol. Hepatol. 10, 473-486. doi: 10.1038/nrgastro.2013.105

Mayer, E. A. (2011). Gut feelings: the emerging biology of gut-brain communication. Nat. Rev. Neurosci. 12, 453-466. doi: 10.1038/ nrn3071

Mayer, E. A., and Hsiao, E. Y. (2017). The Gut and Its Microbiome as Related to Central Nervous System Functioning and Psychological Well-being: Introduction to the Special Issue of Psychosomatic Medicine, Psychosom Med. 79, 844-884. doi: 10.1097/PSY.0000000000000525

Mayer, E. A., Savidge, T., and Shulman, R. J. (2014). Brain-gut microbiome interactions and functional bowel disorders. Gastroenterology. 146, 1500-1512. doi: 10.1053/j.gastro.2014.02.037

Mayer, E. A., Tillisch, K., and Gupta, A. (2015). Gut/brain axis and the microbiota. J. Clin. Invest. 125, 926-938. doi: 10.1172/JCI76304

McConnell, H. L., Kersch, C. N., Woltjer, R. L., and Neuwelt, E. A. (2017). The translational significance of the neurovascular unit. J. Biol. Chem. 292, 762-770. doi: $10.1074 /$ jbc.R116.760215

McCracken, K. W., Catá, E. M., Crawford, C. M., Sinagoga, K. L., Schumacher, M., Rockich, B. E., et al. (2014). Modeling human development and disease in pluripotent stem-cell-derived gastric organoids. Nature 516, 400-404. doi: $10.1038 /$ nature 13863

Meneely, J. P., Chevallier, O. P., Graham, S., Greer, B., Green, B. D., and Elliott, C. T. (2016). $\beta$-methylamino-L-alanine (BMAA) is not found in the brains of patients with confirmed Alzheimer's disease. Sci. Rep. 6:36363. doi: $10.1038 /$ srep36363

Michel, L., and Prat, A. (2016). One more role for the gut: microbiota and blood brain barrier. Ann Transl Med. 4:15. doi: 10.3978/j.issn.2305-5839. 2015.10.16

Mittal, R., Debs, L. H., Patel, A. P., Nguyen, D., Patel, K., O’Connor, G., et al. (2017). Neurotransmitters: the critical modulators regulating gut-brain axis. J. Cell. Physiol. 232, 2359-2372. doi: 10.1002/jcp.25518

Möhle, L., Mattei, D., Heimesaat, M. M., Bereswill, S., Fischer, A., Alutis, M., et al. (2016). Ly6C(hi) monocytes provide a link between antibiotic-induced changes in gut microbiota and adult hippocampal neurogenesis. Cell Rep. 15, 1945-1956. doi: 10.1016/j.celrep.2016.04.074

Moroni, L., Burdick, J. A., Highley, C., Lee, S. J., Morimoto, Y., Takeuchi, S., et al. (2018). Biofabrication strategies for $3 \mathrm{D}$ in vitro models and regenerative medicine. Nat Rev Mat. 3, 21-37. doi: 10.1038/s41578-018-0006-y

Moser, G., Fournier, C., and Peter, J. (2018). Intestinal microbiome-gut-brain axis and irritable bowel syndrome. Wien. Med. Wochenschr. 168, 62-66. doi: 10.1007/s10354-017-0592-0

Mowry, E. M., and Glenn, J. D. (2018). The dynamics of the gut microbiome in multiple sclerosis in relation to disease. Neurol. Clin. 36, 185-196. doi: 10.1016/j.ncl.2017.08.008

Muoio, V., Persson, P. B., and Sendeski, M. M. (2014). The neurovascular unitconcept review. Acta Physiol. 210, 790-798. doi: 10.1111/apha.12250

Naddafi, F., and Mirshafiey, A. (2013). The neglected role of histamine in Alzheimer's disease. Am. J. Alzheimers. Dis. Other Demen. 28, 327-336. doi: 10.1177/1533317513488925

Nakagawa, S., Deli, M. A., Kawaguchi, H., Shimizudani, T., Shimono, T., Kittel, A., et al. (2009). A new blood-brain barrier model using primary rat brain endothelial cells, pericytes and astrocytes. Neurochem. Int. 54, 253-263. doi: 10.1016/j.neuint.2008.12.002

Nakagawa, S., Deli, M. A., Nakao, S., Honda, M., Hayashi, K., Nakaoke, R., et al. (2007). Pericytes from brain microvessels strengthen the barrier integrity in primary cultures of rat brain endothelial cells. Cell. Mol. Neurobiol. 27, 687-694. doi: $10.1007 /$ s10571-007-9195-4
Nemani, K., Hosseini Ghomi, R., McCormick, B., and Fan, X. (2015). Schizophrenia and the gut-brain axis. Prog. Neuropsychopharmacol. Biol. Psychiatry. 56, 155-160. doi: 10.1016/j.pnpbp.2014.08.018

Ochoa-Zarzosa, A., Villarreal-Fernández, E., Cano-Camacho, H., and LópezMeza, J. E. (2009). Sodium butyrate inhibits Staphylococcus aureus internalization in bovine mammary epithelial cells and induces the expression of antimicrobial peptide genes. Microb. Pathog. 47, 1-7. doi: 10.1016/j.micpath.2009.04.006

O’Mahony, S. M., Clarke, G., Borre, Y. E., Dinan, T. G., and Cryan, J. F. (2015). Serotonin, tryptophan metabolism and the brain-gut-microbiome axis. Behav. Brain Res. 277, 32-48. doi: 10.1016/j.bbr.2014.07.027

Park, J., Lee, B. K., Jeong, G. S., Hyun, J. K., Lee, C. J., and Lee, S. H. (2015). Three-dimensional brain-on-a-chip with an interstitial level of flow and its application as an in vitro model of Alzheimer's disease. Lab Chip. 15, 141-150. doi: 10.1039/C4LC00962B

Paşca, A. M., Sloan, S. A., Clarke, L. E., Tian, Y., Makinson, C. D., Huber, N., et al. (2015). Functional cortical neurons and astrocytes from human pluripotent stem cells in 3D culture. Nat. Methods. 12, 671-678. doi: 10.1038/nmeth.3415

Paşca, S. P. (2018). The rise of three-dimensional human brain cultures. Nature 553, 437-445. doi: 10.1038/nature25032

Patabendige, A., Skinner, R. A., Morgan, L., and Abbott, N. J. (2013). A detailed method for preparation of a functional and flexible blood-brain barrier model using porcine brain endothelial cells. Brain Res. 1521, 16-30. doi: 10.1016/j.brainres.2013.04.006

Paxton, N., Smolan, W., Böck, T., Melchels, F., Groll, J., and Jungst, T. (2017). Proposal to assess printability of bioinks for extrusion-based bioprinting and evaluation of rheological properties governing bioprintability. Biofabrication 9:044107. doi: 10.1088/1758-5090/aa8dd8

Perez-Pardo, P., Hartog, M., Garssen, J., and Kraneveld, A. D. (2017) Microbes tickling your tummy: the importance of the gut-brain axis in parkinson's disease. Curr. Behav. Neurosci. Rep. 4, 361-368. doi: 10.1007/s40473-017-0129-2

Perrière, N., Yousif, S., Cazaubon, S., Chaverot, N., F., Bourasset, S., and Cisternino et al. (2007). A functional in vitro model of rat blood-brain barrier for molecular analysis of efflux transporters. Brain Res. 1150, 1-13. doi: 10.1016/j.brainres.2007.02.091

Pistollato, F., Sumalla Cano, S., Elio, I., Masias Vergara, M., Giampieri, F., and Battino, M. (2016). Role of gut microbiota and nutrients in amyloid formation and pathogenesis of Alzheimer disease. Nutr. Rev. 74, 624-634. doi: 10.1093/nutrit/nuw023

Puzan, M., Hosic, S., Ghio, C., and Koppes, A. (2018). Enteric nervous system regulation of intestinal stem cell differentiation and epithelial monolayer function. Sci. Rep. 8:6313. doi: 10.1038/s41598-018-24768-3

Qin, L., Wu, X., Block, M. L., Liu, Y., Breese, G. R., Hong, J. S., et al. (2007). Systemic LPS causes chronic neuroinflammation and progressive neurodegeneration. Glia. 55, 453-462. doi: 10.1002/glia.20467

Rea, K., Dinan, T. G., and Cryan, J. F. (2016). The microbiome: a key regulator of stress and neuroinflammation. Neurobiol. Stress. 4, 23-33. doi: 10.1016/j.ynstr.2016.03.001

Reitz, C., Brayne, C., and Mayeux, R. (2011). Epidemiology of Alzheimer disease. Nat. Rev. Neurol. 7, 137-152. doi: 10.1038/nrneurol.2011.2

Rivière, A., Selak, M., Lantin, D., Leroy, F., and De Vuyst, L. (2016). Bifidobacteria and butyrate-producing colon bacteria: importance and strategies for their stimulation in the human gut. Front. Microbiol. 7:979. doi: 10.3389/fmicb.2016.00979

Rodríguez, J. M., Murphy, K., Stanton, C., Ross, R. P., Kober, O. I., Juge, N., et al. (2015). The composition of the gut microbiota throughout life, with an emphasis on early life. Microb. Ecol. Health Dis. 26:26050. doi: 10.3402/mehd.v26.26050

Rothhammer, V., Borucki, D. M., Tjon, E. C., Takenaka, M. C., Chao, C. C., and Ardura-Fabregat, A. (2018). Microglial control of astrocytes in response to microbial metabolites. Nature 557, 724-728. doi: 10.1038/s41586-018-0119-x

Sampson, T. R., Debelius, J. W., Thron, T., Janssen, S., Shastri, G. G., Ilhan, Z. E., et al. (2016). Gut microbiota regulate motor, deficits and neuroinflammation in a model of Parkinson's disease. Cell 167, 1469-1480.e12. doi: 10.1016/j.cell.2016.11.018

Sánchez-Ferro, Á., Rábano, A., Catalán, M. J., Rodríguez-Valcárcel, F. C., Fernández Díez, S., Herreros-Rodríguez, J., et al. (2015). In vivo gastric 
detection of $\alpha$-synuclein inclusions in Parkinson's disease. Mov. Disord. 30, 517-524. doi: $10.1002 / \mathrm{mds} .25988$

Sarkar, S. R., and Banerjee, S. (2019). Gut microbiota in neurodegenerative disorders. J. Neuroimmunol. 328, 98-104. doi: 10.1016/j.jneuroim.2019.01.004

Saulnier, D. M., Ringel, Y., Heyman, M. B., Foster, J. A., Bercik, P., and Shulman, R. J. (2013). The intestinal microbiome, probiotics and prebiotics in neurogastroenterology. Gut Microbes. 4, 17-27. doi: 10.4161/gmic.22973

Scheuner, D., Eckman, C., Jensen, M., Song, X., Citron, M., Suzuki, N., et al. (1996). Secreted amyloid beta-protein similar to that in the senile plaques of Alzheimer's disease is increased in vivo by the presenilin 1 and 2 and APP mutations linked to familial Alzheimer's disease. Nat. Med. 2, 864-870. doi: $10.1038 / \mathrm{nm} 0896-864$

Schlieve, C. R., Fowler, K. L., Thornton, M., Huang, S., Hajjali, I., Hou, X., et al. (2017). Neural crest cell implantation restores enteric nervous system function and alters the gastrointestinal transcriptome in human tissue-engineered small intestine. Stem Cell Rep. 9, 883-896. doi: 10.1016/j.stemcr.2017.07.017

Schröder, O., Hess, S., Caspary, W. F., and Stein, J. (1999). Mediation of differentiating effects of butyrate on the intestinal cell line Caco2 by transforming growth factor-beta 1. Eur. J. Nutr. 38, 45-50. doi: $10.1007 / \mathrm{s} 003940050045$

Shamir, E. R., and Ewald, A. J. (2014). Three-dimensional organotypic culture: experimental models of mammalian biology and disease. Nat. Rev. Mol. Cell Biol. 15, 647-664. doi: 10.1038/nrm3873

Shankar, G. M., Li, S., Mehta, T. H., Garcia-Munoz, A., Shepardson, N. E., and Smith, I. (2008). Amyloid-beta protein dimers isolated directly from Alzheimer's brains impair synaptic plasticity and memory Nat Med. 14, 837-842. doi: $10.1038 / \mathrm{nm} 1782$

Sheets, S. M., Potempa, J., Travis, J., Casiano, C. A., and Fletcher, H. M. (2005). Gingipains from porphyromonas gingivalis W83 induce cell adhesion molecule cleavage and apoptosis in endothelial cells. Infect. Immun. 73, 1543-1552. doi: 10.1128/IAI.73.3.1543-1552.2005

Sherwin, E., Rea, K., Dinan, T. G., and Cryan, J. F. (2016). A gut (microbiome) feeling about the brain. Curr. Opin. Gastroenterol. 32, 96-102. doi: 10.1097/MOG.0000000000000244

Skaper, S. D., and Facci, L. (2012). Central nervous system neuron-glia co-culture models. Methods Mol. Biol. 846, 79-89. doi: 10.1007/978-1-61779-536-7_8

Skaper, S. D., and Facci, L. (2018). Central nervous system neuron-glia co-culture models and application to neuroprotective agents. Methods Mol. Biol. 1727, 63-80. doi: 10.1007/978-1-4939-7571-6_5

Soscia, D., Belle, A., Fischer, N., Enright, H., Sales, A., Osburn, J., et al. (2017). Controlled placement of multiple CNS cell populations to create complex neuronal cultures. PLoS ONE 12:e0188146. doi: 10.1371/journal.pone.0188146

Stamatovic, S. M., Keep, R. F., and Andjelkovic, A. V. (2008). Brain endothelial cellcell junctions: how to "open" the blood brain barrier. Curr. Neuropharmacol. 6, 179-192. doi: 10.2174/157015908785777210

Stathopoulou, P. G., Galicia, J. C., Benakanakere, M. R., Garcia, C. A., Potempa, J., and Kinane, D. F. (2009). Porphyromonas gingivalis induce apoptosis in human gingival epithelial cells through a gingipain-dependent mechanism. BMC Microbiol. 9:107. doi: 10.1186/1471-2180-9-107

Stilling, R. M., Dinan, T. G., and Cryan, J. F. (2014). Microbial genes, brain \& behaviour - epigenetic regulation of the gut-brain axis. Genes Brain Behav. 13, 69-86. doi: 10.1111/gbb.12109

Sudo, N. (2012). Role of microbiome in regulating the HPA axis and its relevance to allergy. Chem. Immunol. Allergy 98, 163-175. doi: 10.1159/000336510

Sugama, S., Sekiyama, K., Kodama, T., Takamatsu, Y., Takenouchi, T., Hashimoto, M., et al. (2017). Corrigendum to "Chronic restraint stress triggers dopaminergic and noradrenergic neurodegeneration: possible role of chronic stress in the onset of Parkinson's disease" [Brain Behav. Immun. 51 (2016) 39-46]. Brain Behav. Immun. 61:389. doi: 10.1016/j.bbi.2016.12.009

Taché, Y., and Bonaz, B. (2007). Corticotropin-releasing factor receptors and stress-related alterations of gut motor function. J. Clin. Invest. 117, 33-40. doi: 10.1172/JCI30085

Tang-Schomer, M. D., White, J. D., Tien, L. W., Schmitt, L. I., Valentin, T. M., Graziano, D. J., et al. (2014). Bioengineered functional brain-like cortical tissue. Proc. Natl. Acad. Sci. U.S.A. 111, 13811-13816. doi: 10.1073/pnas.1324214111

Tankou, S. K., Regev, K., Healy, B. C., Tjon, E., Laghi, L., Cox, L. M., et al. (2018). A probiotic modulates the microbiome and immunity in multiple sclerosis. Ann. Neurol. 83, 1147-1161. doi: 10.1002/ana.25244
Thomas, C. M., Hong, T., van Pijkeren, J. P., Hemarajata, P., Trinh, D. V., $\mathrm{Hu}, \mathrm{W}$., et al. (2012). Histamine derived from probiotic Lactobacillus reuteri suppresses TNF via modulation of PKA and ERK signaling. PLoS ONE 7:e31951. doi: 10.1371/journal.pone.0031951

Thursby, E., and Juge, N. (2017). Introduction to the human gut microbiota. Biochem. J. 474, 1823-1836. doi: 10.1042/BCJ20160510

Tougas, G. (1999). The autonomic nervous system in functional bowel disorders. Can. J. Gastroenterol. 13(Suppl A), 15A-17A. doi: 10.1155/1999/707105

Tsigos, C., and Chrousos, G. P. (2002). Hypothalamic-pituitary-adrenal axis, neuroendocrine factors and stress. J. Psychosom. Res. 53, 865-871. doi: 10.1016/S0022-3999(02)00429-4

Tufekci, K. U., Genc, S., and Genc, K. (2011). The endotoxin-induced neuroinflammation model of Parkinson's disease. Parkinsons. Dis. 2011:487450. doi: $10.4061 / 2011 / 487450$

Tunesi, M., Fusco, F., Fiordaliso, F., Corbelli, A., Biella, G., and Raimondi, M. T. (2016). Optimization of a 3D dynamic culturing system for in vitro modeling of frontotemporal neurodegeneration-relevant pathologic features. Front. Aging. Neurosci. 8:146. doi: 10.3389/fnagi.2016.00146

Tung, D., Cheung, P. H., Tudor, G., Booth, C., and Saha, S. (2011). In vivo effects of immunomodulators in a murine model of Fluorouracil-induced mucositis. Curr. Ther. Res. Clin. Exp. 72, 262-272. doi: 10.1016/j.curtheres.2011.11.003

Tyakht, A. V., Kostryukova, E. S., Popenko, A. S., Belenikin, M. S., Pavlenko, A. V., Larin, A. K., et al. (2013). Human gut microbiota community structures in urban and rural populations in Russia. Nat. Commun. 4:2469. doi: $10.1038 /$ ncomms3469

Van de Wouw, M., Boehme, M., Lyte, J. M., Wiley, N., Strain, C., O'Sullivan, O., et al. (2018). Short-chain fatty acids: microbial metabolites that alleviate stress-induced brain-gut axis alterations. J. Physiol. 596, 4923-4944. doi: 10.1113/JP276431

Van den Abbeele, P., Belzer, C., Goossens, M., Kleerebezem, M., De Vos, W. M., Thas, O., et al. (2013). Butyrate-producing Clostridium cluster XIVa species specifically colonize mucins in an in vitro gut model. ISME J. 7, 949-961. doi: 10.1038/ismej.2012.158

Van Giau, V., An, S. S. A., and Hulme, J. P. (2018). Mitochondrial therapeutic interventions in Alzheimer's disease. J. Neurol. Sci. 395, 62-70. doi: 10.1016/j.jns.2018.09.033

Vandenhaute, E., Dehouck, L., Boucau, M. C., Sevin, E., Uzbekov, R., and Tardivel, M. (2011). Modeling the neurovascular unit and the blood-brain barrier with the unique function of pericytes. Curr. Neurovasc. Res. 8, 258-269. doi: $10.2174 / 156720211798121016$

Verbeke, K. A., Boobis, A. R., Chiodini, A., Edwards, C. A., Franck, A., Kleerebezem, M., et al. (2015). Towards microbial fermentation metabolites as markers for health benefits of prebiotics. Nutr. Res. Rev. 28, 42-66. doi: 10.1017/S0954422415000037

Veszelka, S., Tóth, A. E., Walter, F. R., Datki, Z., Mózes, E., Fülöp, L., et al. (2013). Docosahexaenoic acid reduces amyloid- $\beta$ induced toxicity in cells of the neurovascular unit. J. Alzheimers. Dis. 36, 487-501. doi: 10.3233/JAD-120163

Vogt, N. M., Kerby, R. L., Dill-McFarland, K. A., Harding, S. J., Merluzzi, A. P., Johnson, S. C., et al. (2017). Gut microbiome alterations in Alzheimer's disease. Sci. Rep. 7:13537. doi: 10.1038/s41598-017-13601-y

Wall, R., Cryan, J. F., Ross, R. P., Fitzgerald, G. F., Dinan, T. G., and Stanton, C. (2014). Bacterial neuroactive compounds produced by psychobiotics. Adv. Exp. Med. Biol. 817, 221-239. doi: 10.1007/978-1-4939-0897-4_10

Walter, F. R., Veszelka, S., Pásztói, M., Péterfi, Z. A., Tóth, A., Rákhely, G., et al. (2015). Tesmilifene modifies brain endothelial functions and opens the blood-brain/blood-glioma barrier. J. Neurochem. 134, 1040-1054. doi: 10.1111/jnc.13207

Wang, F. B., and Powley, T. L. (2007). Vagal innervation of intestines: afferent pathways mapped with new en bloc horseradish peroxidase adaptation. Cell Tissue Res. 329, 221-230. doi: 10.1007/s00441-007-0413-7

Wang, Y., and Kasper, L. H. (2014). The role of microbiome in central nervous system disorders. Brain Behav. Immun. 38, 1-12. doi: 10.1016/j.bbi.2013.12.015

Wang, Y., Wang, L., Zhu, Y., and Qin, J. (2018). Human brain organoidon-a-chip to model prenatal nicotine exposure. Lab Chip. 18, 851-860. doi: 10.1039/C7LC01084B

Wessler, I., and Kirkpatrick, C. J. (2008). Acetylcholine beyond neurons: the nonneuronal cholinergic system in humans. Br. J. Pharmacol. 154, 1558-1571. doi: 10.1038/bjp.2008.185 
Westfall, S., Lomis, N., Kahouli, I., Dia, S. Y., Singh, S. P., and Prakash, S. (2017). Microbiome, probiotics and neurodegenerative diseases: deciphering the gut brain axis. Cell. Mol. Life Sci. 74, 3769-3787. doi: 10.1007/s00018-017-2550-9

Wolf, K. J., Chen, J., Coombes, J. D., Aghi, M. K., and Kumar, S. (2019). Dissecting and rebuilding the glioblastoma microenvironment with engineered materials. Nat. Rev. Mater. 4, 651-668. doi: 10.1038/s41578-019-0135-y

Wood, S. K., and Woods, J. H. (2007). Corticotropin-releasing factor receptor1: a therapeutic target for cardiac autonomic disturbances. Expert Opin. Ther. Targets. 11, 1401-1413. doi: 10.1517/14728222.11.11.1401

Workman, M. J., Mahe, M. M., Trisno, S., Poling, H. M., Watson, C. L., Sundaram, N., et al. (2017). Engineered human pluripotent-stem-cell-derived intestinal tissues with a functional enteric nervous system. Nat. Med. 23, 49-59. doi: $10.1038 / \mathrm{nm} .4233$

Wos-Oxley, M., Bleich, A., Oxley, A. P., Kahl, S., Janus, L. M., Smoczek, A., et al. (2012). Comparative evaluation of establishing a human gut microbial community within rodent models. Gut Microbes 3, 234-249. doi: $10.4161 /$ gmic. 19934

Xue, Q., Liu, Y., Qi, H., Ma, Q., Xu, L., Chen, W., et al. (2013). A novel brain neurovascular unit model with neurons, astrocytes and microvascular endothelial cells of rat. Int. J. Biol. Sci. 9, 174-189. doi: 10.7150/ ijbs. 5115

Yano, J. M., Yu, K., Donaldson, G. P., Shastri, G. G., Ann, P., Ma, L., et al. (2015). Indigenous bacteria from the gut microbiota regulate host serotonin biosynthesis. Cell 161, 264-276. doi: 10.1016/j.cell.2015.02.047

Yarandi, S. S., Peterson, D. A., Treisman, G. J., Moran, T. H., and Pasricha, P. J. (2016). Modulatory effects of gut microbiota on the central nervous system: how gut could play a role in neuropsychiatric health and diseases. J. Neurogastroenterol. Motil. 22, 201-212. doi: 10.5056/jnm 15146
Yi, H. G., Yeong, J. H., Kim, Y., Choi, Y.-J., Moon, H. E., Park, S. H., et al. (2019). A bioprinted human-glioblastoma-on-a-chip for the identification of patient-specific responses to chemoradiotherapy. Nat. Biomed. Eng. 3:519. doi: 10.1038/s41551-019-0363-x

Yoshida, M., Saito, H., and Katsuki, H. (1995). Neurotrophic effects of conditioned media of astrocytes isolated from different brain regions on hippocampal and cortical neurons. Experientia 51, 133-136. doi: 10.1007/BF01929356

Zhao, Y., Jaber, V., and Lukiw, W. J. (2017). Secretory products of the human GI tract microbiome and their potential impact on Alzheimer's disease (AD): detection of lipopolysaccharide (LPS) in AD hippocampus. Front. Cell. Infect. Microbiol. 7:318. doi: 10.3389/fcimb.2017.00318

Zhuang, P., Sun, A. X., An, J., Chua, C. K., and Chew, S. Y. (2018). 3D neural tissue models: From spheroids to bioprinting. Biomaterials 154, 113-133. doi: 10.1016/j.biomaterials.2017.10.002

Zlokovic, B. V. (2011). Neurovascular pathways to neurodegeneration in Alzheimer's disease and other disorders. Nat. Rev. Neurosci. 12, 723-738. doi: $10.1038 / \mathrm{nrn} 3114$

Conflict of Interest: The authors declare that the research was conducted in the absence of any commercial or financial relationships that could be construed as a potential conflict of interest.

Copyright (C) 2020 Raimondi, Izzo, Tunesi, Comar, Albani and Giordano. This is an open-access article distributed under the terms of the Creative Commons Attribution License (CC BY). The use, distribution or reproduction in other forums is permitted, provided the original author(s) and the copyright owner(s) are credited and that the original publication in this journal is cited, in accordance with accepted academic practice. No use, distribution or reproduction is permitted which does not comply with these terms. 